OPEN ACCESS

Edited by:

Raoul Bell,

Heinrich Heine University

of Düsseldorf, Germany

Reviewed by:

Miri Besken,

Bilkent University, Turkey

Charles B. Stone,

John Jay College of Criminal Justice,

United States

*Correspondence:

Fabiana Battista

fabiana.battista@kuleuven.be

tORCID:

Fabiana Battista orcid.org/0000-0003-4086-739X

Henry Otgaar

orcid.org/0000-0002-2782-2181

Specialty section:

This article was submitted to

Cognition,

a section of the journal

Frontiers in Psychology

Received: 16 December 2021

Accepted: 24 January 2022

Published: 24 February 2022

Citation:

Battista F and Otgaar H (2022) Research on the Effects of Lying on Memory: A Scientometric Analysis

and a Call for New Studies.

Front. Psychol. 13:837265.

doi: 10.3389/fpsyg.2022.837265

\section{Research on the Effects of Lying on Memory: A Scientometric Analysis and a Call for New Studies}

\author{
Fabiana Battista $^{1 * t}$ and Henry Otgaar ${ }^{1,2+}$ \\ ${ }^{1}$ Leuven Institute of Criminology, Catholic University of Leuven, Leuven, Belgium, ${ }^{2}$ Department of Clinical Psychological \\ Science, Maastricht University, Maastricht, Netherlands
}

Research on the effects of lying and memory is increasingly attracting empirical attention. In the current manuscript, a scientometric analysis was carried out on the mnemonic consequences of lying. This analysis took into account 70 published articles extracted from Scopus and Web of Science databases from 1998 to 2021. A scientometric analysis was conducted in order to visualize the state of the art on this line of research (i.e., authors, countries, institutions, journals, and co-citations). Additionally, a keywords' cluster analysis was executed to investigate the main keywords used in the published papers. Based on the keywords' cluster analysis, we identified the main aims and critical issues of the reviewed papers. The United States and the Netherlands are the two most productive countries into the effects of lying on memory. The top five authors are mainly from European countries and wrote from 6 to 15 articles. The cluster analysis detected three clusters of keywords. The critical issues of this line of research are mainly related to the generalizability of the achieved findings for real situations, a lack of a direct control of the manipulation adopted, and a need of additional measures. The current analysis provides a comprehensive overview and understanding of existing research on the effects of lying on memory and provides possible future directions of this research domain.

Keywords: lying, memory, scientometric analyses, review, future direction

\section{INTRODUCTION}

It has been widely established that several factors (e.g., cognitive differences, stress, and time) can affect our memory for an event (e.g., Loftus, 2005). Recently, a new line of research is emerging showing that memory can also be contaminated due to the act of lying. This work has shown that memory is differentially affected depending on the type of lie that is executed (e.g., false denial, feigning amnesia, fabricating; e.g., Pickel, 2004; Chrobak and Zaragoza, 2008; Vieira and Lane, 2013; Otgaar et al., 2016; Mangiulli et al., 2018; Romeo et al., 2019; Battista et al., 2020, 2021b; Li and Liu, 2021).

Lying can be defined as "a successful or unsuccessful deliberate attempt, without forewarning, to create in another a belief which the communicator considers to be untrue" (Vrij, 2008, p. 15). Based on this definition, it has been argued that during lying, the truth needs to be inhibited and another and believable alternative needs to be provided (e.g., Vrij, 2008). The act of lying can occur 
in several different ways. Specifically, people can falsely deny, simulate amnesia, and/or fabricate an alternative story (e.g., Goodman-Brown et al., 2003; Pyszora et al., 2003; Bourget and Whitehurst, 2007; Chrobak and Zaragoza, 2008; Block et al., 2012; O'Donohue et al., 2018). Importantly, the type of deceptive strategy can have different impact on memory. Specifically, false denials and feigning amnesia have shown to lead to forgetting while fabrication leads to the formation of commission errors ${ }^{1}$ (Otgaar and Baker, 2018).

\section{STUDYING THE EFFECTS OF LYING ON MEMORY}

Scholars have used different paradigms to examine the impact of lying on memory. For example, in studies on false denials (e.g., Vieira and Lane, 2013; Otgaar et al., 2016, 2018; Battista et al., 2021a; Li and Liu, 2021) researchers typically ask participants to watch some pictures or a video (i.e., mock crime) and subsequently require them to answer some questions regarding the stimulus (i.e., pictures or video) either without guessing or denying the occurrence of several experienced detail. After an interval, participants' memory is tested through a source monitoring task and/or cued questions with the instructions to provide an honest response for all questions. In some studies, participants' memory is tested in terms of memory for the stimulus but also in terms of memory for the interview performed during the first session. Here, the recurrent finding is a memory undermining effect for the interview, termed denial-induced forgetting (DIF; Otgaar et al., 2016; but see also Li and Liu, 2021). That is, people who denied the occurrence of stimulusrelated details are less likely to remember whether they discussed these details during the interview than people who told the truth. A few studies (e.g., Romeo et al., 2018; Battista et al., 2021a) have also shown that, in certain specific circumstances, false denials can also undermine the memory for the event. This seems to occur when the act of denials requires a high involvement, such as an emotional and active involvement (e.g., Romeo et al., 2018) or higher cognitive effort to perform the lie (e.g., Battista et al., 2020).

In studies on feigning amnesia, participants are asked to read a narrative (e.g., Bylin and Christianson, 2002) or watch a mock crime video (e.g., Mangiulli et al., 2019a,b) by identifying themselves as the offender of the crime. Then, participants are asked to either tell the truth concerning the crime or feign memory loss. A week later, all participants are invited to tell the truth regarding the crime. In general, these studies have revealed that feigning amnesia leads to impoverished recall of the crime (e.g., Christianson and Bylin, 1999; Van Oorsouw and Merckelbach, 2004; Van Oorsouw and Giesbrecht, 2008; Mangiulli et al., 2019a,b).

Moreover, scholars have found that feigning amnesia can lead to both omissions and commissions depending on the way in which the liar has simulated amnesia (Otgaar and Baker, 2018).

\footnotetext{
${ }^{1}$ Commission errors occur when people report details not experienced during the original event.
}

That is, if the liar uses a simple lie (e.g., I do not remember what happened), the act of feigning amnesia leads to omissions, while if the liar uses a more elaborated lie (e.g., I do not remember what happened because I was busy with my son), feigning amnesia has been shown to elevate commission errors.

Finally, studies on the effects of fabrication on memory have frequently used the forced confabulation paradigm (e.g., Ackil and Zaragoza, 1998, 2011; Zaragoza et al., 2001). Overall, studies using this paradigm (e.g., Chrobak and Zaragoza, 2008, 2012; Battista et al., 2021b) followed this procedure: Participants watch a video and then reply to some questions regarding the stimulus. A group of them is instructed to honestly answer these questions while a second group has to confabulate an answer. After an interval, participants' memory for the event is assessed. The typical finding here is that people who fabricated details recall their own self-generated detail as true details of the event. In other words, this deceptive strategy leads to commission errors.

Another effect related the effect of fabrication on memory is a phenomenon called the fabrication inflation effect (Polage, 2004, 2012). That is, in these studies (Polage, 2004, 2012, 2018) it was examined whether fabricating an alternative story of the original event can affect people's beliefs in the occurrence of such a fabricated story. Indeed, in these studies, participants -after rating which events were highly unlikely to have been experienced - are invited to provide a false version of the event that was indicated to being never experienced by them (i.e., fabricated experimental event). After a delay (e.g., 1 or 5 weeks), participants are instructed to provide a honest response and rate for a second time beliefs about the occurrence of all the events (i.e., fabricated experimental event vs. control events). She found that a subsample of participants (around 15\% of the total sample) increased their beliefs in the occurrence of the fabricated event compared with the control events.

Otgaar and Baker (2018) proposed the Memory and Deception (MAD) framework to explain the memory outcomes of each deceptive strategy on memory and the possible underlying mechanisms associated with these outcomes. Based on the available literature, they concluded that false denials lead to omissions, feigning amnesia to omissions and commission errors, and fabrication to commission errors. Otgaar and Baker put forward the idea that these different memory effects on memory could be due to the amount of cognitive resources used during the act of lying. In particular, they suggested that each deceptive strategy requires a different amount of cognitive resources and these differences in cognitive resources might underlie the respective outcomes on memory. Therefore, the false denials strategy is assumed to be the simplest strategy and fabrication the most complex one. Furthermore, they postulated that the effects of false denials on memory could also be caused to mechanisms such as inhibition underpinning classical forgetting effects, like the directing forgetting (Basden et al., 1993), retrieval-induced forgetting (Anderson et al., 1994), and forgetting caused by the Think/No Think paradigm (Anderson and Green, 2001). Also, for the memory undermining effect of feigning amnesia they argued that a possible explanation could be a lack of rehearsal (e.g., Christianson and Bylin, 1999; Van Oorsouw and Merckelbach, 2004) of the original information or a 
source monitoring confusion (Johnson et al., 1993) between false and true information. Relatedly, source monitoring errors were regarded as also the most likely explanation underlying the effects of fabrication on memory.

\section{A SCIENTOMETRIC ANALYSIS}

There are several ways to increase our understanding on the effects of lying on memory. One way is to build on previous studies by changing several manipulations thereby examining how these manifest in the effects of lying on memory. Another way is to meta-analytically examine the strengths of the effects of lying on memory. The principal method that we used in the current manuscript was to perform a scientometric analysis to understand the main themes and research questions investigated in studies on lying and memory. The method of scientometric analysis was first defined by Mulchenko (1969) as a quantitative technique to assess the evolution of research. More recently, Hook and Börner (2005) added that scientometric analyses allow researchers to have "the graphic rendering of bibliometric data designed to provide a global view of a particular domain, the structural details of a domain, the salient characteristics of a domain (its dynamics, most cited authors or papers, bursting concepts, etc.) or all three" (p. 201). In other words, scientometric analyses permit researchers to assess the development of a specific research line by assessing authors' and journals' contribution and the impact of publications and to identify the main themes associated with such a specific research domain (Börner et al., 2003; Su and Lee, 2010; Mao et al., 2015; Caffò et al., 2020).

Certain scientometric analyses have also been performed in the area of memory. For instance, Dodier (2019) conducted a bibliometric analysis in the field of recovered memories. The author conducted a series of analyses on research published in the 21st century by using bibliometric information, such as the year of publications, the authors, the country/region of authors, the name of the journals, the number of citations, and keywords. His analysis provides an example of the advantages the findings of such analyses can offer to researchers and a picture of the evaluation of research on repressed and recovered memories. Indeed, the results underlined that the topic captured the attention of several scholars, in different countries, and in different research fields (i.e., clinical and cognitive researchers). In addition, he gave information on the content of articles showing that the debate on the occurrence of recovered and repressed memories remained still stable. Based on these results, the author was able to provide interesting and useful insights for upcoming research by suggesting the need of further investigation on repressed and recovered memories and the need for practitioners (e.g., legal, clinicians) to be aware that the debate surrounding the topic is not over. Similarly, we first wanted to detect the evolution of research in the area of lying and memory. Second, our aim was to identify which critical elements are missing in the area of lying and memory. Specifically, by doing a scientometric analysis, we wanted to collect and provide information (i) on the performance of countries, institutions, and authors to recognize the main actors in this line of research and (ii) on the main challenges and issues addressed by researchers with the aim to highlight possible future research directions. In order to address this second aim, we followed a more traditional review approach by conducting additional analyses on the most representative publications on lying and memory.

\section{METHOD}

\section{Data Collection}

The search of relevant publications was performed by using two databases: Scopus and Web of Science (WoS). ${ }^{2}$ These two databases have been chosen because they are the largest abstract and citations databases of peer-reviewed and multidisciplinary publications (Guz and Rushchitsky, 2009). The literature search on both Scopus and WoS was carried out on October 21st, 2021. No range of years was selected in order to collect all the publications on the topic. For both databases, the search code for retrieving publications was: "Lying and Memory" OR "Deception and Memory" OR "Deceptive Strategies and Memory" OR "False Denials and Memory" OR "Feigned Amnesia and Memory" OR "Simulation of Amnesia and Memory" OR "Fabrication and Memory" OR "Forced Confabulation and Memory" in the "Title, Abstract, Keywords" search in Scopus database and in "Topic" search in WoS. In this way, it was possible to retrieve the following information: Title, Abstract, Authors, Keywords, Keywords Plus, Authors' Information (i.e., country, address, e-mail, ORCID), Publication Information (i.e., journal, date of publication, volume, issue, doi, total citations), and Journal Information (i.e., name, journal abbreviation, ISSN, eISSN). Figure 1 shows how the publications were selected. Scopus and WoS search returned 4059 and 5066 records, respectively. These records were refined by selecting: (i) "Article" and "Review" in the field "Document type, (ii) "Psychology" and "Neuroscience" in the field "Subject Area," and (iii) "English" in the field "Language" of each database. Using this refinement, 306 and 220 papers in Scopus and WoS, respectively, met the criteria and thus two different datasets were extracted in Excel format. Then, they were merged and duplicates were removed, resulting in a dataset of 353 publications. This dataset was further manually reviewed in order to remove unrelated papers. The unrelated papers were all the manuscripts that were detected by Scopus and WoS but did not report studies on the effects of lying on memory for the original event, but rather studies either on deception detection or memory. The final dataset was composed of 70 publications (available on $\mathrm{OSF}^{3}$ ).

\section{Data Analysis}

A plethora of software is available to analyze data with a scientometric approach (e.g., Bibliometrix R Package, BibExcel, CiteSpace, Sci, VOSviewer). For the current work, VOSviewer

${ }^{2}$ In addition, with the aim to gain a complete picture of the literature, we also performed a searching by using ProQuest, an online platform including a large pool of sources, such as full-text journals, articles of newspapers and magazines, and dissertations. However, no records meeting our criteria were detected with ProQuest.

${ }^{3}$ https://osf.io/xe4ty/ 


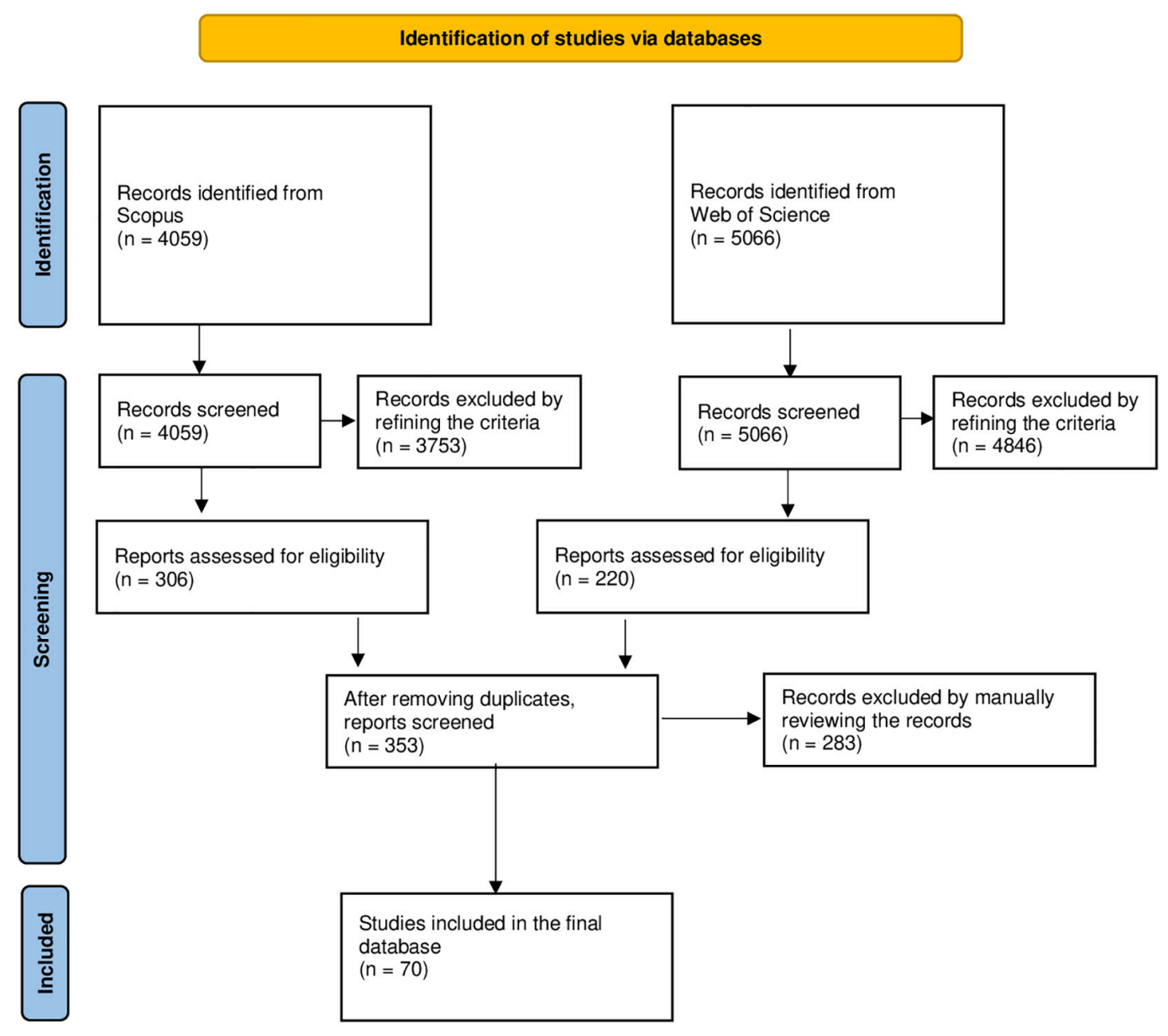

FIGURE 1 | The PRISMA chart showing the selection of the publications.

was used (Van Eck et al., 2010; Van Eck and Waltman, 2014); it is a free software program allowing the creation of bibliometric maps based on bibliographic data (e.g., co-authorship, keyword co-occurrence, citation, co-citation) of the reviewed publications. A performance analysis was conducted on authors, authors' information (i.e., country, affiliated institutions), and publications information (i.e., journal, year of publication, citations) as well as a co-citation analysis on authors and documents. In addition, to identify networks between authors' keywords in the set of publications, a cluster analysis on Keywords Co-Occurrence Network (KCN) was performed. Therefore, based on the publications resulting from the KCN, a targeted overview on the aims, methods, and critical issues related to such a pool of publications was performed.

\section{RESULTS}

\section{Performance of Countries}

The number of publications on the effects of lying on memory by countries is shown in Table $\mathbf{1}$. Specifically, Table 1 shows the publications split based on the number of single
(SCP) and multiple country publications (MCP) for all the countries of the dataset. The SCP refers to publications in which all authors belong to the same country, while the MCP represents publications involving authors of different countries. In the top five of the most productive countries (i.e., United States, Netherlands, United Kingdom, Belgium, Italy), the majority of publications of the leading country the United States - included studies involving scholars of the same country, while the other countries - Netherlands, United Kingdom, Belgium, and Italy - published work that stimulated international collaboration.

An inspection of the number of publications published by country and by year was also conducted. Figure 2 presents a graph of the publications published from 1998 to 2021 in the 12 countries of interest. As can be seen, in the last 3 years (i.e., from 2018 to 2021) literature on the effects of lying on memory has increased. As displayed in Figure 2, the main countries that published the lion's share of articles during this recent peak were the Netherlands, Italy, and Belgium, whereas the United States the leading country in terms of total publications - did not have a peak of publications but instead published at least one paper every year within the period from 1998 to 2021. 
TABLE 1 | Number of publications on the effects of lying on memory by country.

\begin{tabular}{lccc}
\hline Country & Number of Publications & SCP & MCP \\
\hline United States & 28 & 25 & 3 \\
Netherlands & 19 & 4 & 15 \\
United Kingdom & 10 & 4 & 6 \\
Belgium & 10 & 0 & 10 \\
Italy & 9 & 1 & 8 \\
Sweden & 5 & 3 & 2 \\
France & 3 & 3 & 0 \\
China & 1 & 1 & 0 \\
Canada & 1 & 0 & 1 \\
Germany & 1 & 1 & 0 \\
Israel & 1 & 1 & 0 \\
Russia & 1 & 1 & 0
\end{tabular}

SCP indicates Single Country Publications and MCP, Multiple Country Publications. Publications having the first author affiliated to different countries were counted as many times as countries of affiliations.

\section{Performance of Journals}

Table 2 presents the number of publications on the effect of lying on memory by all the journals in the dataset with the total global citation score (TGCS). The TGCS is the number of times the publication has been cited in the database used to download the sources. We obtained the index by summing the citations of all the publications of each journal. In total, work on lying and memory has been published in 25 journals in the research areas of Psychology $(n=22)$, Criminology $(n=2)$, Criminology and Law $(n=1)$. In the top 10 most productive journals - of which 7 in the research area of Psychology, 2 in
Criminology, and 1 in Criminology and Law - 72\% (52/70) of the total publications reaching $68.2 \%$ of total citations $(690 / 1012)$ was published. Specifically, only the leading journal (i.e., Applied Cognitive Psychology) published more than 10 papers on the effects of lying on memory, while three journals (i.e., Memory, Memory and Cognition, and Acta Psychologica) published from 5 to 8 papers, and the rest (i.e., Psychology, Crime, and Law, Journal of Applied Research in Memory and Cognition, Legal and Criminological Psychology, Frontiers in Psychology, Law and Human Behavior, and Psychological Research) from 2 to 4 papers. Regarding the number of citations of the top 10 most productive journals, it is noteworthy that the higher numbers of publications did not necessarily result in having a high number of citations. Indeed, 2 journals (i.e., Applied Cognitive Psychology and Memory and Cognition) reached a very good performance (i.e., more than 100 citations), 6 journals obtained a good performance (i.e., more than 50 citations), and 2 (i.e., Frontiers in Psychology and Psychology, Crime, and Law) a moderately good performance (i.e., less than 40 citations). By contrast, four journals that published only one paper reached a very good or good performance with more than 100 or 50 citations.

\section{Performance of Institutions}

An analysis on the number of publications on the effects of lying on memory by institutions of the first author was performed. This analysis was performed by considering the country, the total global citation scores (TGCS), and the total citations per year (TCpY). Table 3 shows the results for all the institutions of the dataset. We detected 35 institutions which were mainly based in the United States $(n=20)$. However, the majority of the top

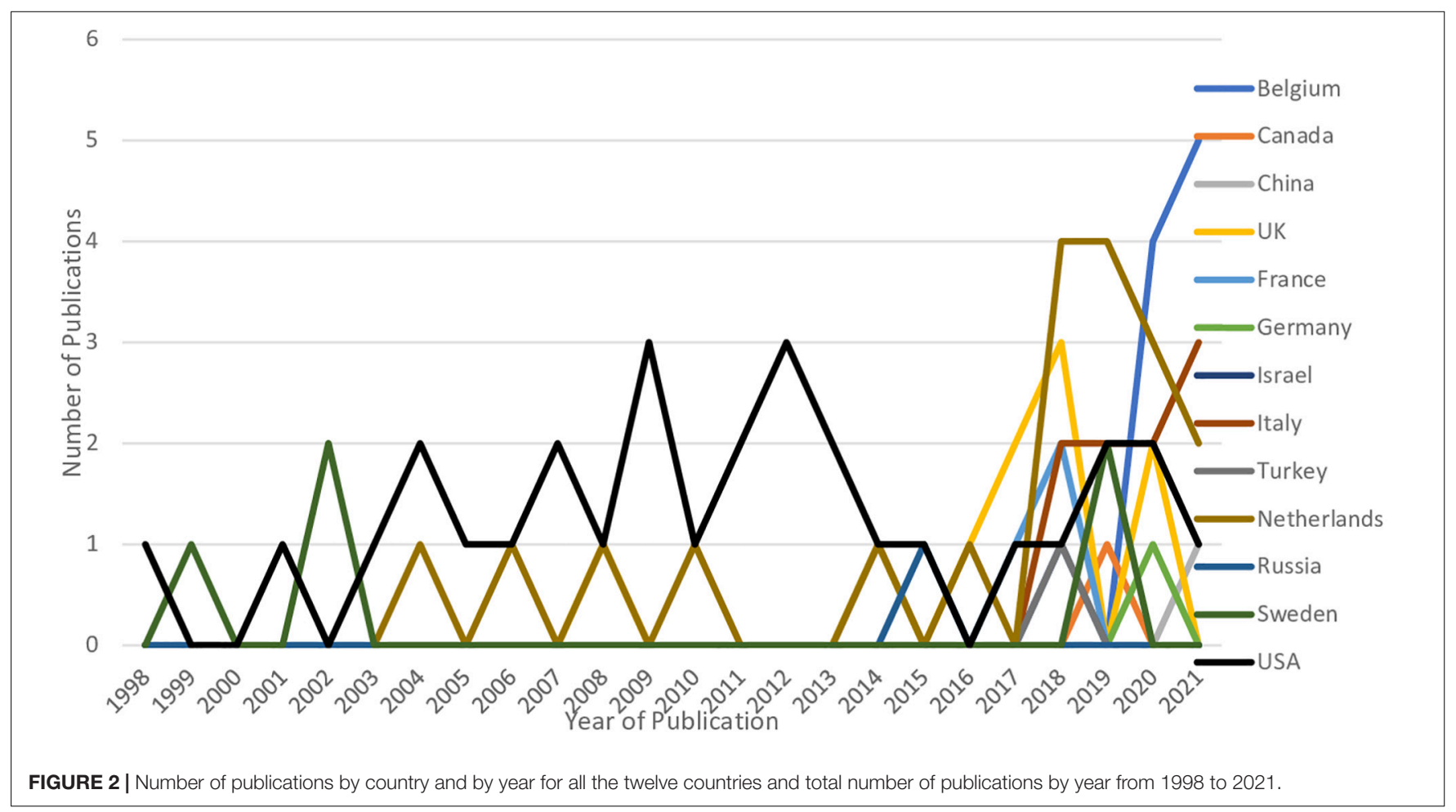


TABLE 2 | Number of publications on the effects of lying on memory by source and total global citation scores (TGCS).

\begin{tabular}{|c|c|c|}
\hline Journal & Number of Publications & TGCS \\
\hline Acta Psychologica & 5 & 52 \\
\hline $\begin{array}{l}\text { American Journal of Forensic } \\
\text { Psychology }\end{array}$ & 1 & 1 \\
\hline American Journal of Psychology & 2 & 17 \\
\hline Applied Cognitive Psychology & 12 & 185 \\
\hline Behavioral Sciences and The Law & 2 & 22 \\
\hline Brain and Cognition & 1 & 2 \\
\hline Cognition & 1 & 2 \\
\hline Developmental Psychology & 1 & 120 \\
\hline Europes Journal of Psychology & 1 & 4 \\
\hline Frontiers in Psychology & 3 & 13 \\
\hline $\begin{array}{l}\text { Journal of Applied Research in Memory } \\
\text { and Cognition }\end{array}$ & 4 & 58 \\
\hline $\begin{array}{l}\text { Journal of Experimental } \\
\text { Psychology-General }\end{array}$ & 1 & 18 \\
\hline $\begin{array}{l}\text { Journal of Experimental } \\
\text { Psychology-Learning, Memory, and } \\
\text { Cognition }\end{array}$ & 1 & 2 \\
\hline Journal of General Psychology & 1 & 0 \\
\hline Law and Human Behavior & 3 & 51 \\
\hline Legal and Criminological Psychology & 4 & 69 \\
\hline Memory & 8 & 57 \\
\hline Memory and Cognition & 7 & 116 \\
\hline Psychological Research & 2 & 53 \\
\hline Psychological Science & 1 & 73 \\
\hline Psychology and Law & 1 & 0 \\
\hline Psychology, Crime, and Law & 4 & 36 \\
\hline Psychonomic Bulletin and Review & 1 & 48 \\
\hline $\begin{array}{l}\text { Quartery Journal of Experimental } \\
\text { Psychology }\end{array}$ & 2 & 10 \\
\hline
\end{tabular}

10 most productive institutions are located in Europe $(n=7)$, with a minority in the United States $(n=3)$. In particular, the leading institutions - having the highest number of publications and TGCS and one of the highest TCpY (19, 199, 11.71, respectively) - was Maastricht University (the Netherlands), followed by the Catholic University of Leuven (Belgium) and the University of Bari Aldo Moro (Italy) with a high number of publications (10 and 8, respectively) and high or good TGCS (31 and 32, respectively) and TCpY (15.5 and 8.00, respectively). The rest of the 10 most productive institutions - from the United Kingdom (i.e., City University of London), United States (Kent State University, Claremont Graduate University, and Central Washington University), France (University of Lille), and Sweden (Stockholm University) - had an average number of publications (from 5 to 3), but high or good TGCS (2661) and TCpY (15.75-2.73). Interestingly, some institutions that published only one article obtained high TGCS and TCpY, i.e., Gustavus Adolphus College (United States, publications: 1, TGCS: 120, and TCpY: 5.22), and Montana State University (United States, publications: 1, TGCS: 45, TCpY: 15.00).

\section{Performance of Authors}

The analysis on the performance of authors was performed. The top 10 most productive authors based on the number of
TABLE 3 | Number of publications on the effects lying on memory by institution, country, number of publications, total global citation scores (TGCS), and total citations per year (TCPY).

\begin{tabular}{|c|c|c|c|c|}
\hline Institutes & Country & Publications & TGCS & TCpY \\
\hline Ball State University & UNITED STATES & 1 & 25 & 1.79 \\
\hline Bar-llan University & ISRAEL & 1 & 12 & 3.00 \\
\hline Bilkent University & TURKEY & 1 & 3 & 0.43 \\
\hline Brandeis University & UNITED STATES & 2 & 3 & 0.43 \\
\hline $\begin{array}{l}\text { Catholic University of } \\
\text { Leuven }\end{array}$ & BELGIUM & 10 & 31 & 15.5 \\
\hline Maastricht University & NETHERLANDS & 19 & 199 & 11.71 \\
\hline $\begin{array}{l}\text { Central Washington } \\
\text { University }\end{array}$ & UNITED STATES & 3 & 34 & 3.78 \\
\hline City University of New York & UNITED STATES & 1 & 3 & 0.75 \\
\hline $\begin{array}{l}\text { Claremont Graduate } \\
\text { University }\end{array}$ & UNITED STATES & 3 & 60 & 6.67 \\
\hline Emporia State University & UNITED STATES & 1 & 17 & 8.50 \\
\hline $\begin{array}{l}\text { Friedrich Schiller University } \\
\text { Jena }\end{array}$ & GERMANY & 1 & 1 & 0.50 \\
\hline Gustavus Adolphus College & UNITED STATES & 1 & 120 & 5.22 \\
\hline Kennesaw State University & UNITED STATES & 1 & 0 & 0 \\
\hline Kent State University & UNITED STATES & 4 & 161 & 8.05 \\
\hline $\begin{array}{l}\text { Lomonosov Moscow State } \\
\text { University }\end{array}$ & RUSSIA & 1 & 0 & 0 \\
\hline Louisiana State University & UNITED STATES & 1 & 19 & 3.17 \\
\hline City University of London & UNITED KINGDOM & 5 & 68 & 13.6 \\
\hline Gothenburg University & SWEDEN & 2 & 15 & 5.00 \\
\hline McGill University & UNITED STATES & 1 & 4 & 1.34 \\
\hline Montana State University & UNITED STATES & 1 & 45 & 15.00 \\
\hline Pepperdine University & UNITED STATES & 1 & 30 & 1.76 \\
\hline Saint Martin's University & UNITED STATES & 1 & 5 & 0.84 \\
\hline $\begin{array}{l}\text { Southern Connecticut } \\
\text { State University }\end{array}$ & UNITED STATES & 1 & 0 & 0 \\
\hline $\begin{array}{l}\text { Southern New Hampshire } \\
\text { University }\end{array}$ & UNITED STATES & 2 & 17 & 0.95 \\
\hline Stockholm University & SWEDEN & 3 & 60 & 2.73 \\
\hline Tianjin Normal University & CHINA & 1 & 0 & 0 \\
\hline University of Aberdeen & UNITED KINGDOM & 2 & 59 & 4.54 \\
\hline University of Bari Aldo Moro & ITALY & 8 & 32 & 8.00 \\
\hline $\begin{array}{l}\text { University of California } \\
\text { Davis }\end{array}$ & UNITED STATES & 1 & 18 & 2.57 \\
\hline University of Denver & UNITED STATES & 1 & 0 & 0 \\
\hline University of Lille & FRANCE & 3 & 63 & 15.75 \\
\hline University of North Carolina & UNITED STATES & 1 & 13 & 1.45 \\
\hline University of Portsmouth & UNITED KINGDOM & 4 & 26 & 6.50 \\
\hline $\begin{array}{l}\text { University of Rome La } \\
\text { Sapienza }\end{array}$ & ITALY & 1 & 2 & 1.00 \\
\hline Wesleyan University & UNITED STATES & 1 & 15 & 1.25 \\
\hline
\end{tabular}

Publications having the first author affiliated to different institutions were counted as many times as institutions of affiliations.

publications are listed in Table 4. In the table, the number of publications for each author is presented by considering the number of single, multi, and first-authored publications. Overall, these authors were involved in $48.57 \%(n=34)$ of the total publications on the effects of lying on memory of which only 5 were single-authored. The first two authors - Otgaar, H., and Mangiulli, I. - of the top 10 most productive authors had more than 10 publications (15 and 13, respectively), followed by Van Oorsouw, K., Zaragoza, M.S. and Battista, F. with more than 5 
TABLE 4 | Number of single, multi, and first-authored publications on the effects of lying on memory by the 10 most productive authors.

\begin{tabular}{|c|c|c|c|c|c|}
\hline Author & Total Publications & Single-Authored & Multi-Authored & First-Authored & Percentage (\%) \\
\hline Ackil, J.K. & 3 & 0 & 3 & 2 & 4.29 \\
\hline Battista, F. & 6 & 0 & 6 & 4 & 8.57 \\
\hline Bylin, S. & 3 & 1 & 2 & 2 & 4.29 \\
\hline Harvey, A.C. & 3 & 0 & 3 & 3 & 4.29 \\
\hline Mangiulli, I. & 13 & 0 & 13 & 5 & 18.57 \\
\hline Otgaar, $\mathrm{H}$. & 15 & 0 & 15 & 5 & 21.43 \\
\hline Pezdek, K. & 3 & 0 & 3 & 2 & 4.29 \\
\hline Polage, D.C. & 4 & 4 & 0 & 1 & 5.71 \\
\hline Riesthuis, P. & 4 & 0 & 4 & 3 & 5.71 \\
\hline Romeo, T. & 3 & 0 & 3 & 2 & 4.29 \\
\hline Van Oorsouw, K. & 8 & 0 & 8 & 4 & 11.43 \\
\hline Zaragoza, M.S. & 7 & 0 & 7 & 1 & 10.00 \\
\hline
\end{tabular}

Percentage was calculated by considering all authors' contributions in the revised publications. Moreover, the list consists of 12 authors because Ackil, J.K., Pezdek, K., and Romeo, T. had the same performance.

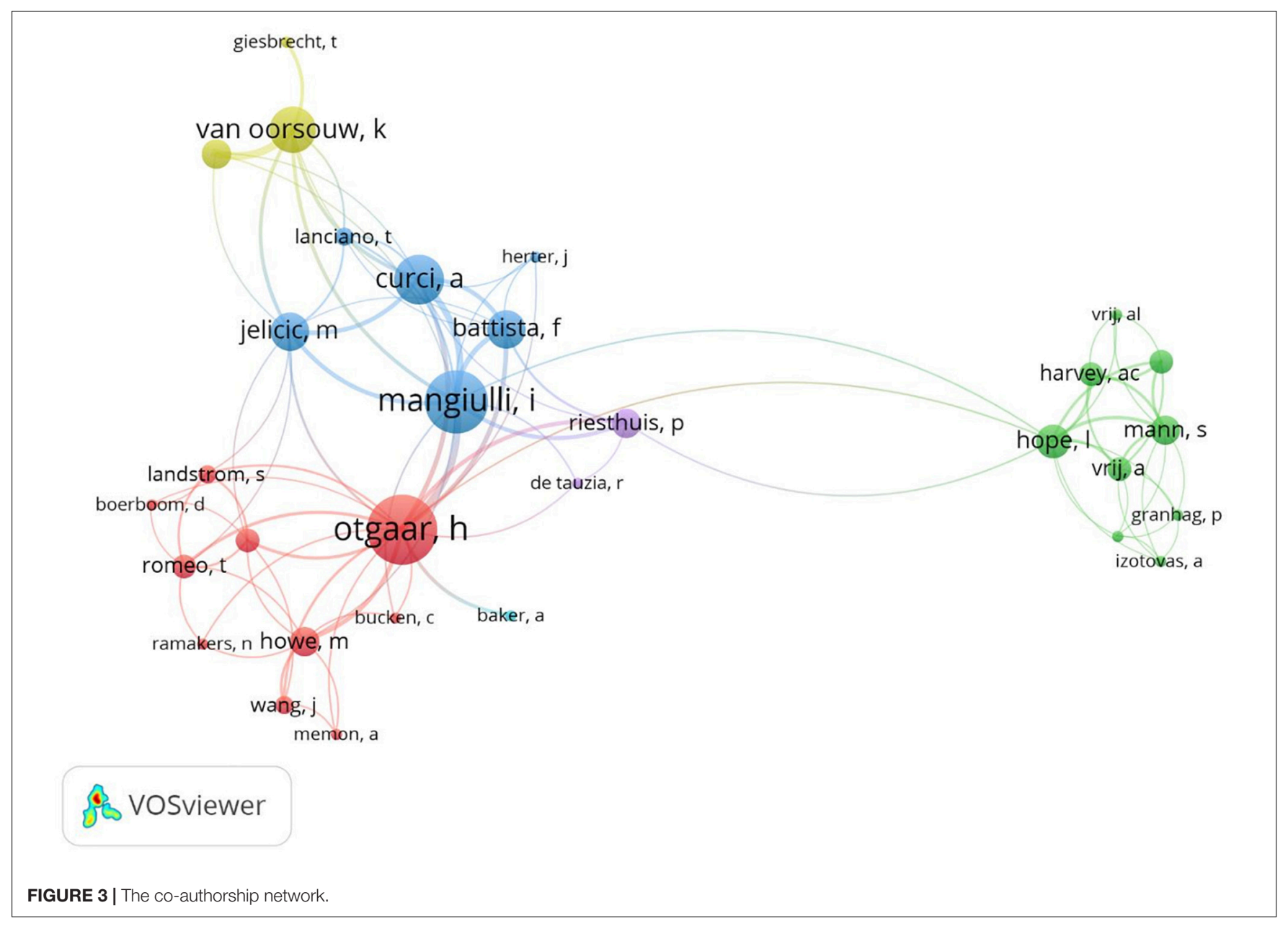

publications $(8,7$, and 6 , respectively) and the rest of the list with 4 or 3 publications. Of interest, more than half of the most productive authors' own publications, except Polage, D. C., were multi-authored publications.

To verify the co-occurrence relationships among authors, a co-authorship analysis was run. Figure 3 shows the co-authorship network with each node representing an author and the lines corresponding to the collaborative actions. The larger the node, the higher the number of the author's publications. Also, the thicker the line, the more collaboration exists between authors. The network demonstrated different research collaborations among scholars, i.e., 98 collaborative actions. In particular, as 
shown in Figure 3 main communities were detected and the authors that predominate the network in terms of both number of publications and collaborative actions were Otgaar, H., Mangiulli, I., Van Oorsouw, K., Curci, A., and Battista, F.

\section{Document Citation Analysis}

Table 5 presents the 10 most cited documents. Specifically, the title of the publication and the number of citations are shown for each publication. The first most cited publication was Ackil and Zaragoza (1998) with more than 100 citations, followed by Zaragoza et al. (2001) with almost 100 citations. Only one publications - Chrobak and Zaragoza (2008) - received more than 50 citations, while the rest of the top 10 most cited articles, i.e., Christianson and Bylin (1999), Pickel (2004), Polage (2004), Van Oorsouw and Merckelbach (2004), Van Oorsouw and Merckelbach (2006), Pezdek et al. (2007), Otgaar and Baker (2018) obtained from 38 to 27 citations.

\section{Author Citation Analysis}

An analysis on the number of citations by authors was performed. Table 6 reports the 10 most cited authors. In the table, the number of citations and the Total Link Strength of the co-authorship links with other authors (TLS) for each author are presented. The first most cited author was Zaragoza, M.S. with more than 300 citations, followed by Ackil, J.K., and van Oorsouw, K. with more than 100 citations and Otgaar, H., with almost 100 citations. The rest of the top 10 most cited authors, i.e., Chrobak, Q. M., Polage, D. C., Bylin, S., Pzedek, K., Christianson, K. A., Mangiulli, I. reported more than 50 citations (from 65 to 55 citations), except Mangiulli, I. that had 36 citations. Interestingly, the majority of these authors reported a low TLS score, except for Otgaar, H., and Mangiulli, I. (15 and 13, respectively).

\section{Document Co-citation Analysis}

A document co-citation analysis (DCA) gives a network of cocited publications by providing the knowledge base of these publications (Li et al., 2017). Specifically, this analysis represents how many times two publications have been jointly cited by other publications (Small, 1973; Zhong et al., 2009). Thus, because the references cited in manuscripts provide the knowledge base of such publications, DCA objectively identified the underpinning knowledge base of the selected publications (Li et al., 2017).
TABLE 6 | The 10 most cited authors.

\begin{tabular}{lcc}
\hline Author & Number of Citations & TLS \\
\hline Ackil, J. K. & 192 & 2.00 \\
Bylin, S. & 61 & 2.00 \\
Christianson, K. A. & 55 & 2.00 \\
Chrobak, Q. M. & 65 & 2.00 \\
Mangiulli, I. & 36 & 13.00 \\
Otgaar, H. & 98 & 15.00 \\
Polage, D. C. & 64 & 0.00 \\
Pzedek, K. & 60 & 3.00 \\
Van Oorsouw, K. & 114 & 8.00 \\
Zaragoza, M. S. & 303 & 6.00 \\
\hline
\end{tabular}

The table shows the number of citations and the Total Link Strength (TLS) by author.

The analysis demonstrated a document co-citation network containing 164 nodes and 2921 links. Each node represents a publication that is identified by the first author name and the publication year, every link is a co-citation relationship between the two corresponding publications, and the size of the node is the co-citation frequency of the publications. As shown in Table 7, the top 10 publications most co-cited were: Ackil and Zaragoza (8 co-citations), Vieira and Lane (2013) (6 co-citations), Zaragoza et al. (2001) (6 co-citations), Van Oorsouw and Merckelbach (2004), Chrobak and Zaragoza (2008), Sun et al. (2009) (all 5 co-citations); Johnson et al. (1993), Anderson and Green (2001), Polage (2012), Walczyk et al. (2014) (all 4 co-citations).

\section{Author Co-citation Analysis}

An author co-citation analysis (ACA) counts the frequency with which any publication of an author is co-cited with another author in the references of citing documents and, therefore, provides the relationships among authors whose publications are cited in the articles (Bayer et al., 1990). Figure 4 displays the author co-citation network, containing 462 nodes and 15518 links. The size of nodes corresponds to the number of authors' co-citations, while the links refer to the indirect cooperative relationships on the basis of the co-citation frequency. The most 10 cited authors were Otgaar, H. (64 co-citations, 306 links, and TLS 58.78), Anderson, M. C. (36 co-citations, 383 links, and TLS 35.07), Vrij (34 co-citations, 265 links, and TLS 32.33), Johnson,

TABLE 5 | The top 10 cited articles.

\begin{tabular}{|c|c|c|}
\hline Authors & Title of the Publication & Citations \\
\hline Ackil and Zaragoza, 1998 & Memorial consequences of forced confabulation: Age differences in susceptibility to false memories & 130 \\
\hline Zaragoza et al., 2001 & Interviewing Witnesses: Forced Confabulation and Confirmatory Feedback Increase False Memories & 98 \\
\hline Chrobak and Zaragoza, 2008 & Inventing stories: Forcing witnesses to fabricate entire fictitious events leads to freely reported false memories & 56 \\
\hline Christianson and Bylin, 1999 & Does simulating amnesia mediate genuine forgetting for a crime event? & 38 \\
\hline Pickel, 2004 & When a lie becomes the truth: The effects of self-generated misinformation on eyewitness memory & 32 \\
\hline Van Oorsouw and Merckelbach, 2004 & Feigning amnesia undermines memory for a mock crime & 32 \\
\hline Pezdek et al., 2007 & Interviewing witnesses: The effect of forced confabulation on event memory & 31 \\
\hline Polage, 2004 & Fabrication deflation? The mixed effects of lying on memory & 30 \\
\hline Van Oorsouw and Merckelbach, 2006 & Simulating amnesia and memories of a mock crime & 28 \\
\hline Otgaar and Baker, 2018 & When lying changes memory for the truth & 27 \\
\hline
\end{tabular}


TABLE 7 | The top 10 co-cited articles.

\begin{tabular}{|c|c|c|}
\hline Authors & Title of the Publication & Co-citations \\
\hline Ackil and Zaragoza, 1998 & Memorial consequences of forced confabulation: Age differences in susceptibility to false memories & 8 \\
\hline Vieira and Lane, 2013 & How you lie affects what you remember & 6 \\
\hline Zaragoza et al., 2001 & Interviewing Witnesses: Forced Confabulation and Confirmatory Feedback Increase False Memories & 6 \\
\hline Chrobak and Zaragoza, 2008 & Inventing stories: Forcing witnesses to fabricate entire fictitious events leads to freely reported false memories & 5 \\
\hline Van Oorsouw and Merckelbach, 2004 & Feigning amnesia undermines memory for a mock crime & 5 \\
\hline Sun et al., 2009 & Does feigning amnesia impair subsequent recall? & 5 \\
\hline Polage, 2012 & Fabrication inflation increases as source monitoring ability decreases & 4 \\
\hline Anderson and Green, 2001 & Suppressing unwanted memories by executive control & 4 \\
\hline Walczyk et al., 2014 & A social-cognitive framework for understanding serious lies: Activation-decision-construction-action theory & 4 \\
\hline Johnson et al., 1993 & Source monitoring. & 4 \\
\hline
\end{tabular}

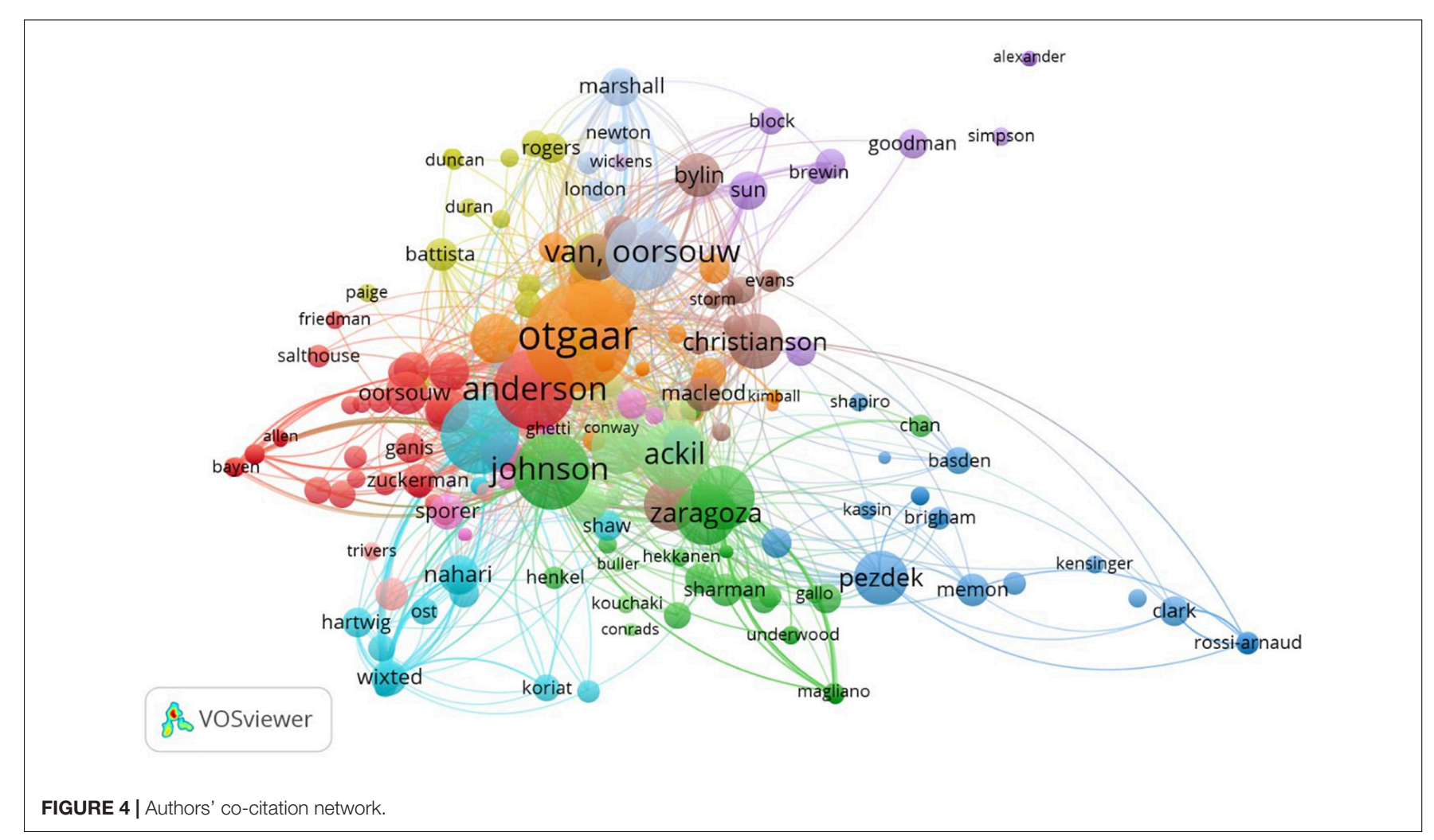

M. K. (33 co-citations, 355 links, and TLS 32.02), Van Oorsouw, K. (30 co-citations, 251 links, and TLS 29.14), Ackil, J. K. (27 co-citations, 339 links, and TLS 26.64), Polage, D. C. (24 cocitations, 254 links, and TLS 23.51), Loftus, E.F. (23 co-citations, 319 links, and TLS 22.44), Zaragoza, M. S. (21 co-citations, 298 links, and TLS 20.69), and Christianson, S. A. (17 co-citations, 307 links, and TLS 16.86).

\section{Cluster Analysis}

With the aim to investigate the semantic data of the published studies, a cluster analysis on the Keywords Co-Occurrence Network (KCN) was carried out. A cluster analysis is a statistical technique that permits to identify the relative degree of correlation of terms and classify a large pool of semantic data pertaining to a specific theme into the same group and data pertaining to a different theme into other groups. In this way, it is possible to identify the themes, trends, and association of a corpus of studies (Olawumi and Chan, 2018; Caffò et al., 2020). The Keyword Co-occurrences (KC) analyses the presence, frequency, and proximity of keywords that - due to their topic - are similar to each other in order to highlight the occurrence of a keyword in at least two papers of a dataset. Therefore, the KCN provides a network composed of different clusters related to each other with a different degree of strength. The strength, called Total Link Strength (TLS), is expressed by a numerical value corresponding to the amount of publications in which two keywords are simultaneously used. The higher this value, the higher is the strength (Radhakrishnan et al., 2017). By using VOSViewer (Van Eck and Waltman, 2014), we used the following parameters for our KNC analysis: "Authors' Keywords," "Fractional counting” (i.e., the links' weight is fractionalized), and 1 as the minimum number of co-occurrences. Therefore, 128 keywords, 16 clusters, 383 links, and a TLS of 109.50 were identified (Supplementary Figure 7). However, in order to have a clear picture of the most 


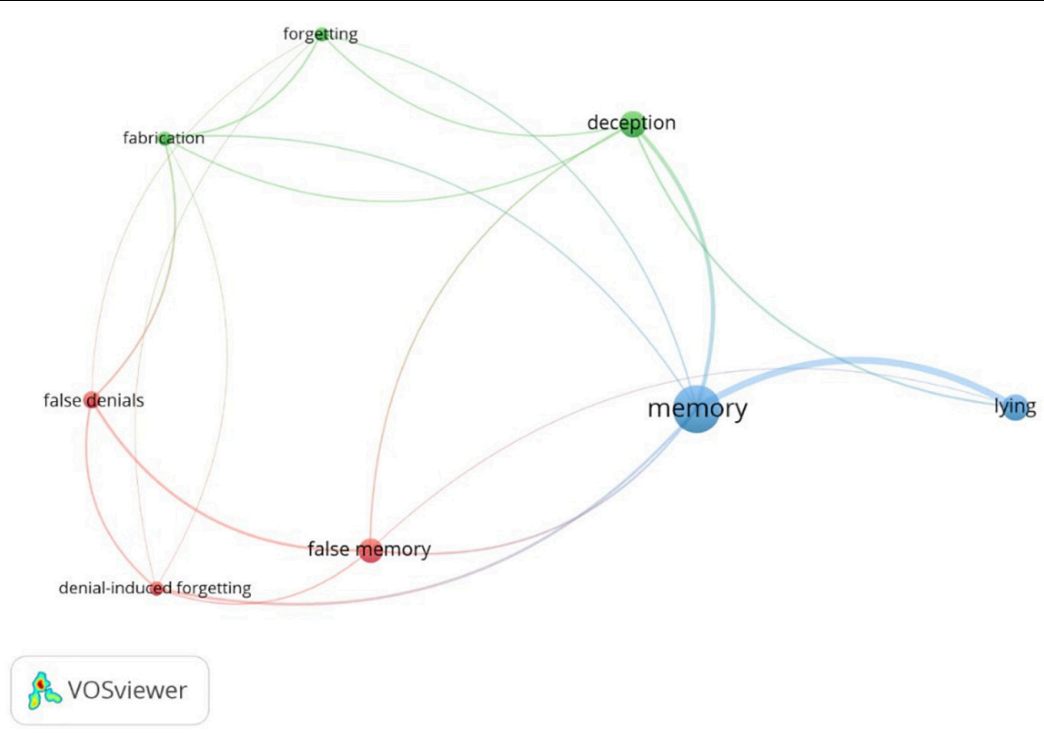

FIGURE 5 | The authors' keywords network.

used keywords, we refined the analysis by adding the option to run the analysis with a co-occurrences threshold (i.e., the minimum number of occurrences of a keyword to enter the network) set on the default value suggested by VOSViewer, i.e., 5. After this selection, 3 clusters, 19 links, and a TLS of 29.00 were detected (Figure 5 and Table 8). Specifically, the analysis identified the following clusters: Cluster 1 consisted of "denialinduced forgetting," "false denials," and "false memory"; Cluster 2 included "deception," "fabrication," and "forgetting"; Cluster 3 was composed of "lying," and "memory." Table 8 shows the three clusters with the corresponding keywords, occurrences, links, TLS. For Cluster 1, the keyword "false memory" was the most cited ( 9 occurrences, 5 links, TLS of 6), followed by "false denials" (both 6 occurrences, 4 links, TLS of 5), and "denialinduced forgetting” (5 occurrences, 5 links, TLS of 5). For Cluster 2, "deception" was the most cited keyword (10 occurrences, 5 links, TLS of 8 ), followed by "fabrication" (5 occurrences, 5 links, TLS of 5), and "forgetting" (both 5 occurrences, 5 links, TLS of 4). Finally, for Cluster 3, the keyword "memory" was the most cited (20 occurrences, 6 links, TLS of 16), followed by "lying" (10 occurrences, 3 links, TLS of 9). In addition, we run an additional analysis in order to check the influence of time on cluster analysis (Figure 6). The time range of clusters (i.e., years in which the keywords in the cluster have been frequently used) was the following: Cluster 1, 2014-2020; Cluster 2, 2017-2020, and Cluster 3, 2017-2018.

\section{Selected Overview}

Based on the cluster analysis, a selected overview was conducted on the publications using the eight keywords detected in the $\mathrm{KCN}$ which amounted to a total of 33 publications. The review was done in order to identify the following studies' information: (i) Main aim, (ii) kind of deceptive strategy employed, (iii) type of stimulus, (iv) type of memory task, (v) significance of the results,
TABLE 8 | Keywords and their occurrences, links, and total link strength (TLS) for the three detected clusters.

\begin{tabular}{lcccc}
\hline Cluster & Keywords & Occurrences & Links & TLS \\
\hline 1 & Denial-Induced Forgetting & 5 & 5 & 5 \\
1 & False Denial & 6 & 4 & 5 \\
1 & False memory & 9 & 5 & 6 \\
2 & Deception & 10 & 5 & 8 \\
2 & Fabrication & 5 & 5 & 5 \\
2 & Forgetting & 5 & 5 & 4 \\
3 & Lying & 10 & 3 & 9 \\
3 & Memory & 20 & 6 & 16 \\
\hline
\end{tabular}

and (vi) limitations. We decided to review this information in order to provide information on the main questions investigated in the considered publications by highlighting the adopted methods and by pointing out their limitations. The information "Main aim," "Deceptive strategy," "Type of stimulus," "Type of memory task," and "Limitations" was simply extracted from each publication and "nd" (i.e., no data) was assigned if no information was detected, while for the information "Significance of the results," we assigned "Yes" if the authors found a statistically significant effect of deception on memory and "No" if the authors did not find any statistically significant effect.

Table 9 shows the authors with the year of publication and the title of the study together with the above-mentioned information (i.e., aim, deceptive strategy, stimulus, memory task, significance of the results, and limitations). With regards to the main goals of the 33 selected publications, for 21 publications the investigated issue was understanding which effects each deceptive strategy (i.e., false denials, feigned amnesia, and fabrication) might have on memory. In addition, 6 publications simultaneously investigated the effects of different deceptive strategies on memory with 5 examining the strategies of both false denials 


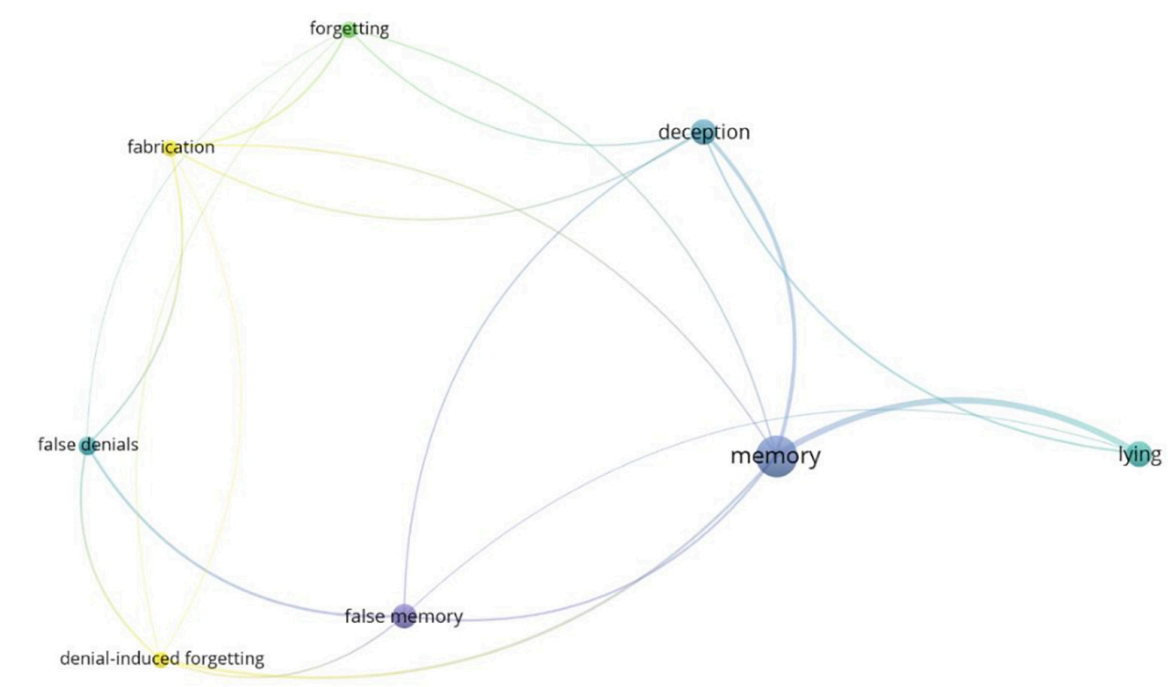

VoSviewer

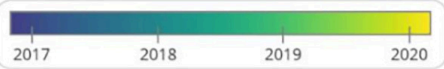

FIGURE 6 | The authors' keywords network considering the influence of time.

and fabrication on memory, while 1 examined the strategies of both false denials and feigned amnesia on memory. Furthermore, 4 publications examined how lying affected liars' beliefs on the occurrence of false events and 1 how the act of repeatedly lying can affect liars' memory for the original event. Finally, 1 of the selected publications aimed to survey people to examine their knowledge and beliefs on how lying affects memory, while 1 was a review on the literature on lying and memory. Regarding the type of deception studied, 21 publications took into consideration the fabrication strategy, 16 the false denials strategy, and 6 the feigned amnesia strategy. Concerning the type of stimulus depicting the event which participants had to lie on, 14 publications used a video, 8 asked participants to perform actions, 4 events list, and 3 showed pictures. Each of all the other stimuli (i.e., narrative, Virtual Reality Scenes, biography, word lists) was used in only 1 publication. With respect to the type of memory task used to verify whether lying had an effect on memory, the principal memory tasks used were free recall and source monitoring (6 publications for both). However, scholars adopted also cued recall, beliefs rating for the memory of false events (i.e., both in 4 publications) or a recognition task (i.e., 3 publications). Interestingly, many publications adopted combined measures of memory. Specifically, 4 studies used both recognition task and cued recall, 3 publications both free and cued recall, and 1 publication both free recall and recognition task. Combining the type of stimulus and memory task, studies using a video as a stimulus mainly used cued recall (i.e., 9 publications) and free recall (i.e., 6 publications) as a memory task. However, the majority of these studies used a combined measure for both types of tasks (i.e., cued recall: 9 publications of which 7 combined with another memory task; free recall: publications of which 4 combined with another memory task). With regards to studies using actions, the free recall, source monitoring, and recognition tasks were used with the same frequency (i.e., 2 publications for each). By contrast, in studies adopting event lists, the most used memory task was the beliefs rating (i.e., 3 publications), while in the case of studies using pictures, the most used task was source monitoring (i.e., 2 publications). Moreover, with regards to the significance of the results achieved in the selected publications, it is noteworthy to underline that all publications, except 2, reported a statistically significant effect of lying on memory. In particular, the majority of the studies found an undermining memory effect of lying by using different stimuli, memory tasks, and by considering the three deceptive strategies. Finally, concerning the main limitations addressed by authors in their publications, the main issues were: (i) the generalizability of the achieved findings for real situations (16 publications), (ii) lack of a direct control of the manipulation adopted (e.g., different type of lying, cognitive load necessary to lie) (10 publications), (iii) need of additional measures (e.g., memory tasks, stimuli, physiological task) (4 publications), (iv) not studied mechanisms underpinning the effects of lying on memory (3 publications), (v) need of investigating different kinds of deception simultaneously (2 publications), (vi) need of considering different perspective taking (1 publication), and (vii) no replication of prior findings (1 publication). In addition, the only review on the topic (i.e., Otgaar and Baker, 2018) underlined a lack of studies on this line of research. In addition, combining the type of stimulus adopted to the limitations reported by the authors, we found that in studies adopting more naturalistic stimuli ${ }^{4}$ (i.e., stimuli

${ }^{4}$ Based on Sonkusare et al.'s (2019) definition, we have considered as naturalistic materials the video, actions, narrative, and the Virtual Reality Scenes stimuli, while the rest of the stimuli were classified as artificial. Thus, the percentage of 
TABLE 9 | Information of the selected publications for the critical review.

\begin{tabular}{|c|c|c|c|c|c|c|c|}
\hline $\begin{array}{l}\text { Authors and } \\
\text { Year }\end{array}$ & Title & Aim & $\begin{array}{l}\text { Deceptive } \\
\text { Strategy }\end{array}$ & Stimulus & Memory Task & $\begin{array}{l}\text { Significance of } \\
\text { the Results }\end{array}$ & Limitations \\
\hline $\begin{array}{l}\text { Battista et al., } \\
2021 a\end{array}$ & $\begin{array}{l}\text { What Can We Remember } \\
\text { After Complex Denials? } \\
\text { The Impact Of Different } \\
\text { False Denials On Memory }\end{array}$ & $\begin{array}{l}\text { Test the effects of two } \\
\text { different cognitively } \\
\text { demanding false denials } \\
\text { on memory }\end{array}$ & False Denials & Video & $\begin{array}{l}\text { Recognition and } \\
\text { Cued Recall }\end{array}$ & Yes & $\begin{array}{l}\text { - Generalization of the } \\
\text { findings for real situations } \\
\text { - Lack of test for the } \\
\text { cognitive manipulation - } \\
\text { Only one strategy - Only } \\
\text { witness perspective }\end{array}$ \\
\hline $\begin{array}{l}\text { Battista et al., } \\
2020\end{array}$ & $\begin{array}{l}\text { The Effects Of Repeated } \\
\text { Denials And Fabrication } \\
\text { On Memory }\end{array}$ & $\begin{array}{l}\text { Test the effect of repeated } \\
\text { lying on memory }\end{array}$ & $\begin{array}{l}\text { False Denials } \\
\text { and Fabrication }\end{array}$ & Video & $\begin{array}{l}\text { Recognition and } \\
\text { Cued Recall }\end{array}$ & Yes & $\begin{array}{l}\text { - Generalization of the } \\
\text { findings for real situations } \\
\text { - Feigned Amnesia not } \\
\text { tested - Mechanisms } \\
\text { Underpinning not studied }\end{array}$ \\
\hline $\begin{array}{l}\text { Battista et al., } \\
2021 \mathrm{c}\end{array}$ & $\begin{array}{l}\text { Do Liars Really } \\
\text { Remember What They } \\
\text { Lied Upon? The Impact } \\
\text { Of Fabrication On } \\
\text { Memory }\end{array}$ & $\begin{array}{l}\text { Test the effects of two } \\
\text { different cognitively } \\
\text { demanding fabrication on } \\
\text { memory }\end{array}$ & Fabrication & Video & $\begin{array}{l}\text { Recognition and } \\
\text { Cued Recall }\end{array}$ & Yes & $\begin{array}{l}\text { - Memory task used in the } \\
\text { pilot study different from } \\
\text { the one of the main study } \\
\text { - No replication of prior } \\
\text { findings on beliefs' rating }\end{array}$ \\
\hline $\begin{array}{l}\text { Battista et al., } \\
2021 b\end{array}$ & $\begin{array}{l}\text { The Role Of Executive } \\
\text { Functions In The Effects } \\
\text { Of Lying On Memory }\end{array}$ & $\begin{array}{l}\text { The role of individual } \\
\text { executive functions } \\
\text { resources in the effects of } \\
\text { lying on memory }\end{array}$ & $\begin{array}{l}\text { False Denials } \\
\text { and Fabrication }\end{array}$ & Video & $\begin{array}{l}\text { Recognition and } \\
\text { Cued Recall }\end{array}$ & Yes & nd \\
\hline Besken, 2018 & $\begin{array}{l}\text { Generating Lies Produces } \\
\text { Lower Memory } \\
\text { Predictions and Higher } \\
\text { Memory Performance } \\
\text { Than Telling the Truth: } \\
\text { Evidence for a } \\
\text { Metacognitive Illusion }\end{array}$ & $\begin{array}{l}\text { Test a lie-generation } \\
\text { manipulation on both } \\
\text { actual and predicted } \\
\text { memory performance }\end{array}$ & Fabrication & $\begin{array}{l}\text { General Events } \\
\text { List }\end{array}$ & Free Recall & Yes & $\begin{array}{l}\text { - Generalization of the } \\
\text { findings for real situations }\end{array}$ \\
\hline $\begin{array}{l}\text { Chrobak and } \\
\text { Zaragoza, } 2012\end{array}$ & $\begin{array}{l}\text { When Forced } \\
\text { Fabrications Become } \\
\text { Truth: Causal } \\
\text { Explanations and False } \\
\text { Memory Development }\end{array}$ & $\begin{array}{l}\text { Test how the formation of } \\
\text { false memory can happen } \\
\text { due to fabrication }\end{array}$ & Fabrication & Video & Free Recall & Yes & $\begin{array}{l}\text { - Generalization of the } \\
\text { findings for other } \\
\text { deceptive strategies }\end{array}$ \\
\hline $\begin{array}{l}\text { Gombos et al., } \\
2012\end{array}$ & $\begin{array}{l}\text { Forced confabulation } \\
\text { affects memory sensitivity } \\
\text { as well as response bias }\end{array}$ & $\begin{array}{l}\text { Test how forced } \\
\text { confabulation affect } \\
\text { memory for the actual } \\
\text { event }\end{array}$ & Fabrication & Video & Cued Recall & Yes & nd \\
\hline $\begin{array}{l}\text { Harvey et al., } \\
2017 a\end{array}$ & $\begin{array}{l}\text { A Stability Bias Effect } \\
\text { Among Deceivers }\end{array}$ & $\begin{array}{l}\text { Test the memory for the } \\
\text { event and stability bias }\end{array}$ & Fabrication & Action & Free Recall & Yes & $\begin{array}{l}\text { - Generalization of the } \\
\text { findings for real situations }\end{array}$ \\
\hline $\begin{array}{l}\text { Harvey et al., } \\
2017 b\end{array}$ & $\begin{array}{l}\text { Deception and Decay: } \\
\text { Verbal Lie Detection as a } \\
\text { Function of Delay and } \\
\text { Encoding Quality }\end{array}$ & $\begin{array}{l}\text { Test how encoding quality } \\
\text { and retention interval } \\
\text { affect memory after lying }\end{array}$ & Fabrication & Video and Action & Cued Recall & Yes & $\begin{array}{l}\text { - Generalization of the } \\
\text { findings for real situations } \\
\text { - Cognitively simple } \\
\text { situation of lying }\end{array}$ \\
\hline Li and Liu, 2021 & $\begin{array}{l}\text { Involvement Modulates } \\
\text { the Effects of Deception } \\
\text { on Memory in Daily Life }\end{array}$ & $\begin{array}{l}\text { Test DIF effect with a daily } \\
\text { life paradigm }\end{array}$ & False Denial & Action & Source Monitoring & Yes & $\begin{array}{l}\text { - Generalization of the } \\
\text { findings due to the } \\
\text { sample composition }\end{array}$ \\
\hline $\begin{array}{l}\text { Mangiulli et al., } \\
2019 a\end{array}$ & $\begin{array}{l}\text { Do Reminders Of The } \\
\text { Crime Reverse The } \\
\text { Memory-Undermining } \\
\text { Effect Of Simulating } \\
\text { Amnesia? }\end{array}$ & $\begin{array}{l}\text { Test whether reminders } \\
\text { about the lied event } \\
\text { reverse the } \\
\text { memory-undermining } \\
\text { effect of feigned amnesia }\end{array}$ & Feigned Amnesia & Video & Free and Cued Recall & Yes & $\begin{array}{l}\text { - Generalization of the } \\
\text { findings for real situations } \\
\text { - Lack of test for the } \\
\text { manipulation adopted - } \\
\text { Not adopted different } \\
\text { memory tasks }\end{array}$ \\
\hline $\begin{array}{l}\text { Mangiulli et al., } \\
2019 b\end{array}$ & $\begin{array}{l}\text { Retrieval-Induced } \\
\text { Forgetting in the Feigning } \\
\text { Amnesia for a Crime } \\
\text { Paradigm }\end{array}$ & $\begin{array}{l}\text { Test whether } \\
\text { retrieval-induced } \\
\text { forgetting underlies the } \\
\text { memory-undermining } \\
\text { effect of feigned amnesia }\end{array}$ & Feigned Amnesia & Video & Free Recall & Yes & $\begin{array}{l}\text { - Generalization of the } \\
\text { findings for real situations } \\
\text { - Lack of test of the } \\
\text { manipulation adopted }\end{array}$ \\
\hline $\begin{array}{l}\text { Mangiulli et al., } \\
2018\end{array}$ & $\begin{array}{l}\text { Feigning Amnesia } \\
\text { Moderately Impairs } \\
\text { Memory for a Mock Crime } \\
\text { Video }\end{array}$ & $\begin{array}{l}\text { Test the effects of feigned } \\
\text { amnesia adopting a video }\end{array}$ & Feigned Amnesia & Video & Free and Cued Recall & Yes & $\begin{array}{l}\text { - Generalization of the } \\
\text { findings for real situations } \\
\text { - No comparison of } \\
\text { different stimuli - Not clear } \\
\text { whether participants } \\
\text { mixed deceptive } \\
\text { strategies - Need to use } \\
\text { questionnaire to assess } \\
\text { cognitive functions }\end{array}$ \\
\hline $\begin{array}{l}\text { McWilliams et al., } \\
2014\end{array}$ & $\begin{array}{l}\text { Memory For Child Sexual } \\
\text { Abuse Information: } \\
\text { Simulated Memory Error } \\
\text { And Individual Differences }\end{array}$ & $\begin{array}{l}\text { Test the effects of } \\
\text { simulated memory (i.e., } \\
\text { false denied or fabricated } \\
\text { details) error on memory } \\
\text { for CSA information }\end{array}$ & $\begin{array}{l}\text { False Denials } \\
\text { and Fabrication }\end{array}$ & Narrative & Free and Cued Recall & Yes & $\begin{array}{l}\text { - Generalization of the } \\
\text { findings for real situations } \\
\text { - Lack of control for the } \\
\text { adopted memory tasks }\end{array}$ \\
\hline
\end{tabular}


TABLE 9 | (Continued)

\begin{tabular}{|c|c|c|c|c|c|c|c|}
\hline $\begin{array}{l}\text { Authors and } \\
\text { Year }\end{array}$ & Title & Aim & $\begin{array}{l}\text { Deceptive } \\
\text { Strategy }\end{array}$ & Stimulus & Memory Task & $\begin{array}{l}\text { Significance of } \\
\text { the Results }\end{array}$ & Limitations \\
\hline $\begin{array}{l}\text { Otgaar and } \\
\text { Baker, 2018* }\end{array}$ & $\begin{array}{l}\text { When Lying Changes } \\
\text { Memory For The Truth }\end{array}$ & $\begin{array}{l}\text { Review literature on the } \\
\text { effects of lying and } \\
\text { memory }\end{array}$ & $\begin{array}{l}\text { False Denials, } \\
\text { Feigned } \\
\text { Amnesia, and } \\
\text { Fabrication }\end{array}$ & nd & nd & nd & - Lack of studies \\
\hline $\begin{array}{l}\text { Otgaar et al., } \\
2020\end{array}$ & $\begin{array}{l}\text { The Impact Of False } \\
\text { Denials On Forgetting And } \\
\text { False Memory }\end{array}$ & $\begin{array}{l}\text { Test the effect of false } \\
\text { denials on forgetting and } \\
\text { false memory formation }\end{array}$ & False Denials & Word Lists & $\begin{array}{l}\text { Free Recall or Source } \\
\text { Monitoring }\end{array}$ & Yes & $\begin{array}{l}\text { - Generalization of the } \\
\text { findings for real situations }\end{array}$ \\
\hline $\begin{array}{l}\text { Otgaar et al., } \\
2016\end{array}$ & $\begin{array}{l}\text { Denial-Induced Forgetting: } \\
\text { False Denials Undermine } \\
\text { Memory, But External } \\
\text { Denials Undermine Belief }\end{array}$ & $\begin{array}{l}\text { Test the effects of false } \\
\text { denials on memory }\end{array}$ & False Denials & $\begin{array}{l}\text { Pictures and } \\
\text { Video }\end{array}$ & Source Monitoring & Yes & nd \\
\hline $\begin{array}{l}\text { Otgaar et al., } \\
2018\end{array}$ & $\begin{array}{l}\text { Forgetting Having Denied: } \\
\text { The Amnesic } \\
\text { Consequences Of Denial }\end{array}$ & $\begin{array}{l}\text { Test the DIF effect for } \\
\text { different memory tasks }\end{array}$ & False Denials & Video & $\begin{array}{l}\text { Free Recall or Source } \\
\text { Monitoring }\end{array}$ & Yes & $\begin{array}{l}\text { - Generalization of the } \\
\text { findings for real situations }\end{array}$ \\
\hline Paige et al., 2019 & $\begin{array}{l}\text { Influence Of Age On The } \\
\text { Effects Of Lying On } \\
\text { Memory }\end{array}$ & $\begin{array}{l}\text { Test the effects of lying } \\
\text { considering the role of } \\
\text { cognitive control }\end{array}$ & $\begin{array}{l}\text { False Denials and } \\
\text { Fabrication }\end{array}$ & Action & Recognition & Yes & $\begin{array}{l}\text { - Lack of test of the } \\
\text { measure adopted }\end{array}$ \\
\hline Paige et al., 2020 & $\begin{array}{l}\text { Evaluating Heart Rate } \\
\text { Variability As A Predictor } \\
\text { Of The Influence Of Lying } \\
\text { On Memory }\end{array}$ & $\begin{array}{l}\text { Test whether heart rate } \\
\text { variability is involved in the } \\
\text { effects of lying one } \\
\text { memory }\end{array}$ & $\begin{array}{l}\text { False Denials and } \\
\text { Fabrication }\end{array}$ & Action & Recognition & Yes & $\begin{array}{l}\text { - Not adopted different } \\
\text { individual differences } \\
\text { measures - Need to use } \\
\text { physiological measures }\end{array}$ \\
\hline $\begin{array}{l}\text { Pezdek et al., } \\
2007\end{array}$ & $\begin{array}{l}\text { Interviewing Witnesses: } \\
\text { The Effect Of Forced } \\
\text { Confabulation On Event } \\
\text { Memory }\end{array}$ & $\begin{array}{l}\text { Test whether forced } \\
\text { confabulation can } \\
\text { increase the recall of } \\
\text { details never occurred }\end{array}$ & Fabrication & Video & Cued Recall & Yes & $\begin{array}{l}\text { - Generalization of the } \\
\text { findings for real situations }\end{array}$ \\
\hline Polage, 2017 & $\begin{array}{l}\text { The Effect of Telling Lies } \\
\text { on Belief in the Truth }\end{array}$ & $\begin{array}{l}\text { Test the effects of lying on } \\
\text { beliefs in the memory for } \\
\text { the truth }\end{array}$ & Fabrication & Events List & Belief Rating & Yes & $\begin{array}{l}\text { - Need of more control on } \\
\text { the manipulation adopted } \\
\text { - Mechanisms } \\
\text { Underpinning not studied }\end{array}$ \\
\hline Polage, 2012 & $\begin{array}{l}\text { Fabrication Inflation } \\
\text { Increases As Source } \\
\text { Monitoring Ability } \\
\text { Decreases }\end{array}$ & $\begin{array}{l}\text { Test the effects of lying on } \\
\text { beliefs in a false childhood } \\
\text { event }\end{array}$ & Fabrication & Events List & Belief Rating & Yes & $\begin{array}{l}\text { - Mechanisms } \\
\text { Underpinning not studied }\end{array}$ \\
\hline Polage, 2018 & $\begin{array}{l}\text { Liar, Liar: Consistent Lying } \\
\text { Decreases Belief In The } \\
\text { Truth }\end{array}$ & $\begin{array}{l}\text { Test the effects of lying on } \\
\text { beliefs in participants' } \\
\text { childhood events }\end{array}$ & False Denials & Events List & Belief Rating & Yes & $\begin{array}{l}\text { - Lack of direct measure } \\
\text { of memory for the event - } \\
\text { Lack of control of the } \\
\text { manipulation adopted }\end{array}$ \\
\hline $\begin{array}{l}\text { Riesthuis et al., } \\
2021 \text { a }\end{array}$ & $\begin{array}{l}\text { Public Beliefs On The } \\
\text { Relationship Between } \\
\text { Lying And Memory }\end{array}$ & $\begin{array}{l}\text { Survey beliefs of students } \\
\text { and general public on the } \\
\text { effects of lying and } \\
\text { memory }\end{array}$ & $\begin{array}{l}\text { False Denials, } \\
\text { Feigned } \\
\text { Amnesia, and } \\
\text { Fabrication }\end{array}$ & nd & nd & nd & nd \\
\hline $\begin{array}{l}\text { Riesthuis et al., } \\
2021 b^{\star}\end{array}$ & $\begin{array}{l}\text { Registered Report: The } \\
\text { Effects Of Incentivized Lies } \\
\text { On Memory }\end{array}$ & $\begin{array}{l}\text { Test the effect of deceptive } \\
\text { behavior on memory }\end{array}$ & Fabrication & Action & Cued Recall & nd & nd \\
\hline $\begin{array}{l}\text { Riesthuis et al., } \\
2020\end{array}$ & $\begin{array}{l}\text { Adopting A Fictitious } \\
\text { Autobiography: } \\
\text { Fabrication Inflation Or } \\
\text { Deflation? }\end{array}$ & $\begin{array}{l}\text { Test whether adopting a } \\
\text { fictitious biography make } \\
\text { participants believe in the } \\
\text { fake autobiography }\end{array}$ & Fabrication & Biography & Belief Rating & no & $\begin{array}{l}\text { - Generalization of the } \\
\text { findings }\end{array}$ \\
\hline $\begin{array}{l}\text { Romeo et al., } \\
2019\end{array}$ & $\begin{array}{l}\text { The Impact Of Lying About } \\
\text { A Traumatic Virtual Reality } \\
\text { Experience On Memory }\end{array}$ & $\begin{array}{l}\text { Test the effects of lying in } \\
\text { a virtual reality paradigm }\end{array}$ & $\begin{array}{l}\text { False Denials and } \\
\text { Fabrication }\end{array}$ & $\begin{array}{l}\text { Virtual Reality } \\
\text { Scenes }\end{array}$ & Source Monitoring & Yes & nd \\
\hline $\begin{array}{l}\text { Romeo et al., } \\
2018\end{array}$ & $\begin{array}{l}\text { The Memory-Impairing } \\
\text { Effects Of Simulated } \\
\text { Amnesia For A Mock } \\
\text { Crime }\end{array}$ & $\begin{array}{l}\text { Test the memory } \\
\text { undermining effect for } \\
\text { crime-related details }\end{array}$ & $\begin{array}{l}\text { False Denials and } \\
\text { Feigned Amnesia }\end{array}$ & Action & Source Monitoring & Yes & $\begin{array}{l}\text { - Generalization of the } \\
\text { findings for real situations } \\
\text { - Lack of control on the } \\
\text { manipulation adopted }\end{array}$ \\
\hline $\begin{array}{l}\text { Rossi-Arnaud } \\
\text { et al., } 2020\end{array}$ & $\begin{array}{l}\text { Long-Lasting Positive } \\
\text { Effects Of Collaborative } \\
\text { Remembering On False } \\
\text { Assents To Misleading } \\
\text { Questions }\end{array}$ & $\begin{array}{l}\text { Test the effects of } \\
\text { collaborative remembering } \\
\text { on the recall of } \\
\text { self-generated details }\end{array}$ & Fabrication & Video & $\begin{array}{l}\text { Free Recall and } \\
\text { Recognition }\end{array}$ & No & $\begin{array}{l}\text { - Need of different } \\
\text { manipulations }\end{array}$ \\
\hline $\begin{array}{l}\text { Van Oorsouw } \\
\text { and Giesbrecht, } \\
2008\end{array}$ & $\begin{array}{l}\text { Minimizing Culpability } \\
\text { Increases Commission } \\
\text { Errors In A Mock Crime } \\
\text { Paradigm }\end{array}$ & $\begin{array}{l}\text { Test whether minimizing } \\
\text { culpability undermines } \\
\text { memory for the original } \\
\text { event lied upon }\end{array}$ & Fabrication & Action & Free Recall & Yes & $\begin{array}{l}\text { - Need of extra check on } \\
\text { the manipulation adopted }\end{array}$ \\
\hline $\begin{array}{l}\text { Vieira and Lane, } \\
2013\end{array}$ & $\begin{array}{l}\text { How You Lie Affects What } \\
\text { You Remember }\end{array}$ & $\begin{array}{l}\text { Test how false denials } \\
\text { affects memory }\end{array}$ & False Denials & Pictures & Source Monitoring & Yes & $\begin{array}{l}\text { - Generalization of the } \\
\text { findings for real situations }\end{array}$ \\
\hline Vo et al., 2021 & $\begin{array}{l}\text { How Deception And } \\
\text { Believability Feedback } \\
\text { Affect Recall }\end{array}$ & $\begin{array}{l}\text { Test whether fabricating } \\
\text { details and receiving } \\
\text { believability feedback } \\
\text { impacts memory }\end{array}$ & Fabrication & Pictures & Recognition & Yes & $\begin{array}{l}\text { - Generalization of the } \\
\text { findings for real situations } \\
\text { - Need of extra check on } \\
\text { the manipulation adopted }\end{array}$ \\
\hline
\end{tabular}


that employ rich, multimodal dynamics) the main limitations were: (i) the generalizability of the achieved findings for real situations (12 publications), (ii) lack of a direct control of the manipulation (9 publications), (iii) need of additional measures (e.g., memory tasks, stimuli, physiological task) (4 publications), (iv) not studied mechanisms underpinning the effects of lying on memory (1 publication), ( $v$ ) need of investigating different kinds of deception simultaneously (2 publications), (vi) need of considering different perspective taking (1 publication). However, for studies with more artificial stimuli (stimuli that do not employ the rich, multimodal dynamics) the main limitations were: (i) the generalizability of the achieved findings for real situations (4 publications), (ii) lack of a direct control of the manipulation (1 publication), and (iii) not studied mechanisms underpinning the effects of lying on memory (2 publications).

\section{DISCUSSION}

The aim of the present study was to perform a scientometric analysis and provide a selected overview of literature about the effects of lying on memory. Our principal reason for undertaking such analysis was to provide a comprehensive picture of the state of the art on this topic and identify needs for future research topics. We performed a literature search by using Scopus and Web of Science and we collected 70 publications from 1998 to 2021 (October 21st). Our results showed the following.

To begin with, a performance analysis was conducted on countries, journals, institutions, and authors' performance. The United States was the leading country in terms of the amount of publications on the effects of lying on memory followed by the Netherlands. Most publications from the United States were single country publications suggesting that they were not the result of international collaborations. By contrast, publications from the Netherlands - and the other countries (i.e., Belgium, United Kingdom, Italy) - were mainly multilab publications, thus demonstrating that this line of research encouraged collaborations among scholars of different countries. It is interesting to mention that when we further investigated countries' performance, we found that this index is strictly related to the year of publications. That is, we found that the United States published a high number of publications from 1998 to $2014(24 / 28)^{5}$, while a peak of publications in recent years, specifically from 2018 to 2021, was registered for the Netherlands, Italy, and Belgium $(13 / 19,9 / 9,9 / 10 \text {, respectively })^{6}$. Therefore, this seems to suggest that these last three countries were the ones that recently were mostly involved in the investigation of the effects of lying on memory by strengthening international collaborations. In addition, these results underline that a gap

\footnotetext{
naturalistic and artificial materials in studies on the effects of lying on memory was $75 \%(n=24)$ and $25 \%(n=9)$, respectively.

${ }^{5}$ The number of publications reported between parentheses refers to the number of publications of the country from 1998 to 2017 by the total number of publications of the country.

${ }^{6}$ The number of publications reported between parentheses refers to the number of publications of the country from 2018 to 2021 by the total number of publications of the country.
}

between the United States and European countries (such as the Netherlands, Italy, and Belgium) is increasing in the last years resulting in a leading role of the European countries in this line of research.

In order to understand a possible reason for these results, we checked if this shift in countries' performance could correspond to a switch of attention in the deceptive strategy investigated and whether authors mentioned in their manuscript a reasoning why they were interested in a specific deceptive strategy. Most studies (70\%) conducted in the United States aimed to investigate the effects of fabrication on memory, while European countries also conducted research on the effects of false denials and feigning amnesia (51\% in total, $23 \%$ false denials, $28 \%$ feigned amnesia). Consequently, the peak of publications from 2018 to 2021 suggests that the shift in countries was also a shift in research into the memory effects of different strategies of deception. Interestingly, the general reasoning reported by the authors to examine the effects of deceptive strategies on memory was similar in the majority of the publications regardless of the country. Indeed, in around $70 \%$ of publications, the authors argued to be interested in reproducing the real legal situations in which people deceive in an experimental setting. This argumentation was also provided in publications from American and European countries and both before and during the peak of publications (2018-2021).

However, when we looked specifically at the legal cases provided as examples in which different kinds of deception can occur, we found different reasons based on the type of deception investigated. In particular, 24 studies on fabrication referred to legal cases in which interviewers used suggestive tactics forcing the interviewee (i.e., witness, suspect, or victim) to provide information (i.e., lie by fabricating). Specifically, in several of these studies, these cases referred to situations in which children were interviewed and pressured to provide information. In contrast to this, in all publications on feigning amnesia, the authors examined this deceptive strategy because they related it to cases in which offenders use this strategy in order to obstruct investigations and interfere with legal proceedings. Finally, the main reason in publications on false denials (17 publications) was that victims of sexual abuse sometimes falsely deny being abused because they do not want to disclose a traumatic event (e.g., sexual abuse). Specifically, while presenting examples of real cases, scholars mostly reported situations in which children who are victims of sexual abuse deny such abuse during the very first interviews and come forward with the truth in later interviews. These different reasons provide a plausible explanation for the interests of different types of deception on memory across time.

Regarding the performance of journals, more than $70 \%$ of publications was published in 10 journals. The first journal was Applied Cognitive Psychology with more than ten publications. This is not surprising considering that this journal has specific attention for studies on autobiographical memory, the detection of deception, eyewitness memory, and statement reliability. The other journals publishing a high number of publications (5-8 publications) were Memory, Memory and Cognition, and Acta Psychologica. Again, this was not surprising based on the aim of the journals, Memory and Memory and Cognition, i.e., publishing experimental work in all the areas of memory and cognition (e.g., 
learning, decision making, problem solving). In addition, based on the scope of Acta Psychologica to publish a broader range of psychological research areas (e.g., social psychology, clinical psychology, individual differences, etc.), the high number of publications in this journal leads to the conclusion that scholars published their work on the effects of lying on memory not only in journals with a specific focus on how memory works, but also in journals promoting more general areas. This probably results from a desire of scholars to make this work visible to a higher number of people due to the strong practical implications of this work for practitioners (e.g., judges, police officers, etc.).

Moreover, we took into consideration the journals' citation scores and we again found that Applied Cognitive Psychology and Memory and Cognition had a high performance in terms of citations with more than 100 citations. However, we additionally discovered that the number of publications in journals did not necessarily reflect the quantity of citations. Indeed, on the one hand, we found that many of the most productive journals did not have a high or good performance in terms of citations, while on the other hand, some of the journals that published only one paper reported a high performance in terms of citations. A possible explanation for this could be that the citation score strictly depends on specific indexes of the journals (e.g., the impact factor) that permit a large spreading of the publications. Therefore, a comparison of the performance among journals based on the number of citations might not provide accurate information on journals' productivity.

Concerning the institutions' performance, the analysis showed that - even if more than half of the institutions are based in the United States - the most productive institutions were from Europe, with Maastricht University (the Netherlands) being the most productive together with the Catholic University of Leuven (Belgium) and the University of Bari Aldo Moro (Italy). This is in line with our results on countries' performance by time showing that in the last years the geographic area mainly involved in the investigations of the effects of lying on memory has shifted from the United States to Europe. Once again, the citation scores (Total Global Citation Score and Total Citation per Year) did not go at the same pace as the number of publications. Based also on the countries' performance by time, it could be argued that the citation scores of some of the European most productive institutions were lower than other American less productive institutions because the publications from such American institutions were published many years before the European ones. This could have made such publications more detectable and citable.

Finally, regarding the analysis on performance, the one conducted on authors' performance demonstrated that the most two prolific authors with more than 10 publications were Otgaar, H. and Mangiulli, I., followed by van Oorsouw, K., Zaragoza, M.S. and Battista, F. (8-6 publications).

When a co-authorship analysis was executed, the same authors - plus Curci, A. and except Zaragoza, M.S., - were detected to be the scholars that stimulated collaborations among scholars. This was also confirmed with the type of publications, i.e., single-author or multi-author, showing that none of the above-mentioned authors published single-author studies.
The further analysis on the frequency with which publications and authors were cited (i.e., document citation analysis and author citation analysis) and co-cited (i.e., document co-citation analysis and authors' co-citation analysis) showed interesting results. Specifically, we first found that the most cited publications were articles published from the 1998 to 2001 (e.g., Ackil and Zaragoza, 1998; Zaragoza et al., 2001; Christianson and Bylin, 1999; Pickel, 2004; Chrobak and Zaragoza, 2008). This seems to confirm that, in general, the citations performance is related to the year of publication of the papers. That is, in general, it might be that actors (i.e., journals, institutions, countries, authors) having a higher number of citations are the ones that published work on lying and memory in the early stage of this line of research (i.e., 1998-2001). In addition, we found that some of the most co-cited documents (i.e., Johnson et al., 1993; Anderson and Green, 2001; Walczyk et al., 2014) were publications not directly investigating the effects of lying on memory. However, these publications were about memory mechanisms or frameworks that are used to explain how lying can affect memory. Thus, it is reasonable to assume that they were cited by authors in order to examine possible mechanisms underpinning the effects of deceptive strategies on memory or in order to explain the act of lying. Similarly, results on the author citations score showed that the most cited author was Zaragoza, M. S. Interestingly, the author's co-citation analysis also highlighted that several co-cited authors were scholars (i.e., Anderson, Vrij, and Loftus) who did not carry out research specifically focused on the relationship between lying and memory, but rather focused on the two topics separately. Still, the explanation provided for the results of the DCA can fit these findings.

The cluster analysis conducted on authors' keywords allowed us to identify the most used keywords gathering in clusters. Because our aim was to summarize the main trends within the literature on the effects of lying on memory, we set a co-occurrences threshold using the default value among those available. Hence, we distinguished three clusters and eight keywords meaning that the most representative and used keywords used in publications on the effects of lying on memory are eight and can be collapsed in three major groups. In particular, examining the detected keywords for each cluster, the first cluster identified keywords more related to the publication on the false denial strategy, the second cluster on feigned amnesia and fabrication, while the third cluster included general keywords not attributable to the investigation of a specific deceptive strategy. Hence, based on the identified clusters, it is reasonable to argue that a high number of publications are only centered on the mnemonic effects of false denials, while publications on the consequences of feigned amnesia and fabrication on memory are more related to each other.

The cluster analysis was also used to select the publications on which we conducted a further investigation. The review was done in order to better understand the main issues investigated so far and how they were investigated with the final aim to provide helpful suggestions for future research. Hence, we critically reviewed the aims, methods, and limitations of the selected studies. The combination of this information allows to have a more comprehensive understanding of the studies 
published so far and can be summarized as follows. Concerning the main goals addressed in the selected studies, the majority of the studies examined the effects of lying on memory by considering the effects of each deceptive strategy (i.e., false denials, feigned amnesia, and fabrication) at once, while just a few compared two strategies in only one study. Additionally, a few studies were interested in understanding how lying can change people's beliefs in the occurrence of false events. Finally, only one study addressed whether and how repeatedly lying affects liars' memory. In addition, the event information on which participants had to lie upon was mainly presented by using a video of a mock crime video (i.e., theft) or by asking them to perform actions (i.e., stealing objects or daily life experience). Interestingly, only the minority of studies used pictures or narratives. Moreover, the memory scores used to test a possible impairment in terms of forgetting or memory distortions (i.e., omissions and commissions) due to having lied were free recall scores or source monitoring scores.

It is noteworthy to underline that some studies used in their experiment multiple types of memory scores, like for instance both recognition and cued recall scores or cued and free recalls. All the findings observed in these studies were statistically significant and, specifically, demonstrated that overall lying on an event leads to a detrimental effect on memory. Finally, when we looked at the limitations stated by the authors in their papers, almost all the scholars indicated as a principal issue the impossibility to completely generalize the findings in real situations due to several reasons (Pezdek et al., 2007; Vieira and Lane, 2013; McWilliams et al., 2014; Harvey et al., 2017a,b; Besken, 2018; Mangiulli et al., 2018, 2019a,b; Otgaar et al., 2018, 2020; Battista et al., 2020, 2021a; Riesthuis et al., 2020; Li and Liu, 2021; Vo et al., 2021). In particular, the main reasons reported to explain this issue were (i) the use of a sample of the population (i.e., students) being not necessarily representative of the general population (ii) the stimulus adopted lacking of ecological validity. A second limitation was a lack in directly controlling the manipulation used during the lying phase (Van Oorsouw and Giesbrecht, 2008; McWilliams et al., 2014; Polage, 2017, 2018; Romeo et al., 2018; Mangiulli et al., 2019a,b; Paige et al., 2019; Battista et al., 2021a; Vo et al., 2021). That is, in several publications, the authors investigated the different kinds of deception by manipulating the cognitive effort required to lie or by adapting certain paradigms to fit with the research aim, but they did not provide any evidence of the supposed direction of the manipulation but instead just assumed it based on prior studies. Another important limitation raised was the need to test the variables of the study by using a larger pool of measures (Mangiulli et al., 2018, 2019a; Polage, 2018; Paige et al., 2020). In other words, several scholars underlined that multiple measures of the same investigated concept (i.e., memory, physiological, individual differences) should be combined. Still, a further limitation was the impossibility of these studies to provide a clear understanding of the mechanism underpinning the mnemonic consequences of lying (Polage, 2012, 2017; Battista et al., 2020). Indeed, the majority of studies carried out were not able to test which mechanisms (i.e., inhibition, retrievalinduced forgetting, source monitoring errors) can explain why lying undermines the memory for the original event but rather provided speculation about their results. Finally, some scholars also pointed out the need to take into consideration whether the perspective-taking (i.e., witness, offender, or victim) matters in the effects of lying on memory (Battista et al., 2021a) and the need also to simultaneously compare all the three strategies (i.e., false denials, feigned amnesia, and fabrication) (Battista et al., 2020, 2021a).

Taken together, our scientometric analysis has several implications. First, the general picture is that lying can adversely affect memory. This conclusion seems to be supported by the different type of stimuli and memory tasks adopted. Indeed, although studies used different materials and measures in accordance with the specific goal of the study, the recurrent finding was that there is a statistically significant difference between liars and truth-tellers in the recall of the original event and that such a recall is worst in liars than in truth-tellers. However, to truly capture this effect, meta-analytic studies should be conducted on the effect of lying on memory. Second, because the main goal of the studies was to test each strategy at once, there is also a large consensus on the idea that each strategy affects memory in its own way. This is in line with the main assumption of the Memory and Deception model (MAD; Otgaar and Baker, 2018). However, it is also interesting to underline that so far no studies have tested the effects of all the three strategies on memory simultaneously. This is surprising because in order to conclude that each strategy affects memory differently it is necessary having a direct comparison among the strategies in one single study. Third, based on the limitations that the authors stated in their papers, it is evident that further investigation requires to fill the gaps of the published studies. For instance, considering the practical implications of this work, it is important that future studies adopt a more ecological valid procedure (e.g., using emotional stimuli, Virtual Reality scenes) and include more representative samples of populations (e.g., people with different range of age). Similarly, it is necessary that future studies will try to replicate findings by considering other possible factors that matter in real situations, such the role of the liar (i.e., witness, offender, or victim) or other variables not considered so far, like the delay of time between the act of lying and the recall of the original event or which type of information is susceptible to forgetting after lying. Furthermore, an important future step is trying to collect more evidence on the possible mechanisms underpinning the effects of lying on memory.

\section{CONCLUDING REMARKS}

We have presented the first scientometric analysis on the effects of lying on memory combined with a selected review. By adopting this combined review approach, we were able to provide relevant information on research not only in terms of countries, institutions, journals, and authors' performance but only in terms of detection of the research themes, methodology, and limitations, and challenges for future research. Our findings showed that the (experimental) investigation of the effects of lying and memory is increasing in the last years (i.e., 2018-2021). 
The number of collaborative actions among scholars seems to be limited to few authors, suggesting that the research on this topic has captured the attention of a small group of researchers belonging to the same community. In addition, the selected review highlighted the need to continue investigating the topic by adopting more ecological paradigms and trying to provide information on un-answered questions.

This work provides useful information for researchers interested in investigating how lying affects memory by underlying that this line of research is an emerging field that necessitates further attention.

\section{DATA AVAILABILITY STATEMENT}

The datasets presented in this study can be found in online repositories. The names of the repository/repositories and

\section{REFERENCES}

Ackil, J. K., and Zaragoza, M. S. (1998). Memorial consequences of forced confabulation: age differences in susceptibility to false memories. Dev. Psychol. 34, 1358-1372. doi: 10.1037/0012-1649.34.6.1358

Ackil, J. K., and Zaragoza, M. S. (2011). Forced fabrication versus interviewer suggestions: differences in false memory depend on how memory is assessed. Appl. Cogn. Psychol. 25, 933-942. doi: 10.1002/acp.1785

Anderson, M. C., and Green, C. (2001). Suppressing unwanted memories by executive control. Nature 410, 366-369. doi: 10.1038/35066572

Anderson, M. C., Bjork, R. A., and Bjork, E. L. (1994). Remembering can cause forgetting: retrieval dynamics in long-term memory. J. Exp. Psychol. Learn. Mem. Cogn. 20, 1063-1087. doi: 10.1037/0278-7393.20.5.1063

Basden, B. H., Basden, D. R., and Gargano, G. J. (1993). Directed forgetting in implicit and explicit memory tests: a comparison of methods. J. Exp. Psychol. Learn. Mem. Cogn. 19, 603-616. doi: 10.1037/0278-7393.19.3.603

Battista, F., Otgaar, H., Mangiulli, I., and Curci, A. (2021b). The role of executive functions in the effects of lying on memory. Acta Psychol. 215:103295. doi: 10.1016/j.actpsy.2021.103295

Battista, F., Curci, A., Mangiulli, I., and Otgaar, H. (2021a). What can we remember after complex denials? The impact of different false denials on memory. Psychol. Crime Law 27, 914-931. doi: 10.1080/1068316X.2020.1865956

Battista, F., Mangiulli, I., Riesthuis, P., Curci, A., and Otgaar, H. (2021c). Do liars really remember what they said? The impact of fabrication on memory. Memory 29, 1076-1090. doi: 10.1080/09658211.2021.1960380

Battista, F., Mangiulli, I., Curci, A., Herter, J., and Otgaar, H. (2020). The effects of repeated false denials and fabrication on memory. J. Cogn. Psychol. 32, 1-13. doi: 10.1080/20445911.2020.1767626

Bayer, A. E., Smart, J. C., and McLaughlin, G. W. (1990). Mapping intellectual structure of a scientific subfield through author co-citations. J. Am. Soc. Inf. Sci. (1986-1998) 41, 6.

Besken, M. (2018). Generating lies produces lower memory predictions and higher memory performance than telling the truth: evidence for a metacognitive illusion. J. Exp. Psychol. Learn. Mem. Cogn. 44:465. doi: 10.1037/xlm0000459

Block, S. D., Shestowsky, D., Segovia, D. A., Goodman, G. S., Schaaf, J. M., and Alexander, K. W. (2012). "That never happened": adults' discernment of children's true and false memory reports. Law Hum. Behav. 36, 365-374. doi: 10.1037/h0093920

Börner, K., Chen, C., and Boyack, K. W. (2003). Visualizing knowledge domains. Annu. Rev. Inf. Sci. Technol. 37, 179-255. doi: 10.1002/aris.1440370106

Bourget, D., and Whitehurst, L. (2007). Amnesia and crime. J. Am. Acad. Psychiatry Law Online 35, 469-480.

Bylin, S., and Christianson, S. A (2002). Characteristics of malingered amnesia: consequences of withholding vs. distorting information on later memory of a crime event. Legal Criminol. Psychol. 7, 45-61. doi: 10.1348/135532502168379

Caffò, A. O., Tinella, L., Lopez, A., Spano, G., Massaro, Y., Lisi, A., et al. (2020). The drives for driving simulation: a scientometric analysis and a selective review accession number(s) can be found below: Open Science Framework: https://osf.io/xe4ty/.

\section{AUTHOR CONTRIBUTIONS}

FB conceived the study, conducted data searching, analyzed the data, and wrote the manuscript. HO critically revised the manuscript. Both authors contributed to the article and approved the submitted version.

\section{SUPPLEMENTARY MATERIAL}

The Supplementary Material for this article can be found online at: https://www.frontiersin.org/articles/10.3389/fpsyg. 2022.837265/full\#supplementary-material

of reviews on simulated driving research. Front. Psychol. 11:917. doi: 10.3389/ fpsyg.2020.00917

Christianson, S. Å., and Bylin, S. (1999). Does simulating amnesia mediate genuine forgetting for a crime event? Appl. Cogn. Psychol. 13, 495-511. doi: 10.1002/ (sici)1099-0720(199912)13:6<495::aid-acp615<3.0.co;2-0

Chrobak, Q. M., and Zaragoza, M. S. (2008). Inventing stories: forcing witnesses to fabricate entire fictitious events leads to freely reported false memories. Psychonom. Bull. Rev. 15, 1190-1195. doi: 10.3758/pbr.15.6.1190

Chrobak, Q. M., and Zaragoza, M. S. (2012). "The misinformation effect," in Suggestibility in Legal Contexts: Psychological Research and Forensic Implications, eds A. M. Ridley, F. Gabbert, and D. J. La Rooy (London: Wiley Blackwell), 21-44. doi: 10.1002/9781118432907.ch2

Dodier, O. (2019). A bibliometric analysis of the recovered memory controversy in the 21st century. Appl. Cogn. Psychol. 33, 571-584. doi: 10.1002/acp.3498

Gombos, V., Pezdek, K., and Haymond, K. (2012). Forced confabulation affects memory sensitivityas well as response bias. Mem. Cogn. 40, 127-134. doi: 10 . 3758/s13421-011-0129-5

Goodman-Brown, T. B., Edelstein, R. S., Goodman, G. S., Jones, D. P. H., and Gordon, D. S. (2003). Why children tell: a model of children's disclosure of sexual abuse. Child Abuse Neglect 27, 525-540. doi: 10.1016/S0145-2134(03) 00037-1

Guz, A. N., and Rushchitsky, J. J. (2009). Scopus: a system for the evaluation of scientific journals. Int. Appl. Mech. 45, 351-362. doi: 10.1007/s10778-0090189-4

Harvey, A. C., Vrij, A., Hope, L., Leal, S., and Mann, S. (2017a). A stability bias effect among deceivers. Law Hum. Behav. 41, 519-529. doi: 10.1037/lhb0000258

Harvey, A. C., Vrij, A., Leal, S., Hope, L., and Mann, S. (2017b). Deception and decay: verbal lie detection as a function of delay and encoding quality. J. Appl. Res. Mem. Cogn. 6, 306-318. doi: 10.1016/j.jarmac.2017.04.002

Hook, P. A., and Börner, K. (2005). "Educational knowledge domain visualizations: tools to navigate, understand, and internalize the structure of scholarly knowledge and expertise," in New Directions in Cognitive Information Retrieval, eds A. Spink and C. Cole (Dordrecht: Springer), 187-208. doi: 10.1007/1-40204014-8_10

Johnson, M. K., Hashtroudi, S., and Lindsay, D. S. (1993). Source monitoring. Psychol. Bull. 114, 3-28. doi: 10.1037/0033-2909.114.1.3

Li, X., Ma, E., and Qu, H. (2017). Knowledge mapping of hospitality research- A visual analysis using CiteSpace. Int. J. Hosp. Manag. 60, 77-93. doi: 10.1016/j. ijhm.2016.10.006

Li, Y., and Liu, Z. (2021). Involvement modulates the effects of deception on memory in daily life. Front. Psychol. 12:756297. doi: 10.3389/fpsyg.2021.756297

Loftus, E. F. (2005). Planting misinformation in the human mind: a 30-year investigation of the malleability of memory. Learn. Mem. 12, 361-366. doi: 10.1101/lm.94705

Mangiulli, I., Lanciano, T., Jelicic, M., van Oorsouw, K., Battista, F., and Curci, A. (2018). Can implicit measures detect source information in crime-related amnesia? Memory 26, 1019-1029. doi: 10.1080/09658211.2018.1441421 
Mangiulli, I., Van Oorsouw, K., Curci, A., and Jelicic, M. (2019a). Retrieval-induced forgetting in the feigning amnesia for a crime paradigm. Front. Psychol. 10:928. doi: 10.3389/fpsyg.2019.00928

Mangiulli, I., Lanciano, T., van Oorsouw, K., Jelicic, M., and Curci, A. (2019b). Do reminders of the crime reverse the memory-undermining effect of simulating amnesia? Mem. Cogn. 47, 1375-1385. doi: 10.3758/s13421-019-00939-z

Mao, G., Liu, X., Du, H., Zuo, J., and Wang, L. (2015). Way forward for alternative energy research: a bibliometric analysis during 1994-2013. Renew. Sust. Energ. Rev. 48, 276-286. doi: 10.1016/j.rser.2015.03.094

McWilliams, K., Goodman, G. S., Lyons, K. E., Newton, J., and Avila-Mora, E. (2014). Memory for child sexual abuse information: simulated memory error and individual differences. Mem. Cogn. 42, 151-163. doi: 10.3758/s13421-0130345-2

Mulchenko, Z. M. (1969). Measurement of Science. Study of the Development of Science as an Information process. USAF Foreign Technology Division Translation AD735634. Springfield, VA: National Technical Information Service.

O'Donohue, W., Cummings, C., and Willis, B. (2018). The Frequency of false allegations of child sexual abuse: a critical review. J. Child Sex. Abuse 27, 459-475. doi: 10.1080/10538712.2018.1477224

Olawumi, T. O., and Chan, D. W. M. (2018). A scientometric review of global research on sustainability and sustainable development. J. Clean. Prod. 183, 231-250. doi: 10.1016/j.jclepro.2018.02.162

Otgaar, H., and Baker, A. (2018). When lying changes memory for the truth. Memory 26, 2-14. doi: 10.1080/09658211.2017.1340286

Otgaar, H., Howe, M. L., Mangiulli, I., and Bücken, C. (2020). The impact of false denials onforgetting and false memory. Cognition 202:104322. doi: 10.1016/j. cognition.2020.104322

Otgaar, H., Howe, M. L., Smeets, T., and Wang, J. (2016). Denial-induced forgetting: false denials undermine memory, but external denials undermine belief. J. Appl. Res. Mem. Cogn. 5, 168-175. doi: 10.1016/j.jarmac.2016.0 4.002

Otgaar, H., Romeo, T., Howe, M. L., and Ramakers, N. (2018). Forgetting having denied: the "amnesic" consequences of denial. Mem. Cogn. 46, 520-529. doi: 10.3758/s13421-017-0781-5

Paige, L. E., Fields, E. C., and Gutchess, A. (2019). Influence of age on the effects of lying on memory. Brain Cogn. 133, 42-53. doi: 10.1016/j.bandc.2018.10.002

Paige, L. E., Wolf, J. M., and Gutchess, A. (2020). Evaluating heart rate variability as a predictor of the influence of lying on memory. Memory 1-11. doi: 10.1080/ 09658211.2020.1849307

Pezdek, K., Sperry, K., and Owens, S. M. (2007). Interviewing witnesses: the effect of forced confabulation on event memory. Law Hum. Behav. 31, 463-478. doi: 10.1007/s10979-006-9081-5

Pickel, K. (2004). When a lie becomes the truth: the effects of self-generated misinformation on eyewitness memory. Memory 12, 14-26. doi: 10.1080/ 09658210244000072

Polage, D. (2017). The effect of telling lies on belief in the truth. Eur. J. Psychol. 13, 633-644. doi: 10.5964/ejop.v13i4.1422

Polage, D. C. (2004). Fabrication deflation? The mixed effects of lying on memory. Appl. Cogn. Psychol. 18, 455-465. doi: 10.1002/acp.995

Polage, D. C. (2012). Fabrication inflation increases as source monitoring ability decreases. Acta Psychol. 139, 335-342. doi: 10.1016/j.actpsy.2011.12.007

Polage, D. C. (2018). Liar, liar: consistent lying decreases belief in the truth. Appl. Cogn. Psychol. 33, 527-536. doi: 10.1002/acp.3489

Pyszora, N. M., Barker, A. F., and Kopelman, M. D. (2003). Amnesia for criminal offences: a study of life sentence prisoners. J. Forensic Psychiatry 14, 475-490. doi: 10.1080/14789940310001599785

Radhakrishnan, S., Erbis, S., Isaacs, J. A., and Kamarthi, S. (2017). Novel keyword co-occurrence network-based methods to foster systematic reviews of scientific literature. PLoS One 12:e172778. doi: 10.1371/journal.pone.0172778

Riesthuis, P., Otgaar, H., Battista, F., and Mangiulli, I. (2021a). Public beliefs on the relationship between lying and memory. Psychol. Crime Law 1-24. doi: 10.1080/1068316X.2021.1929979

Riesthuis, P., Otgaar, H., Hope, L., and Mangiulli, I. (2021b). Registered report: the effects of incentivized lies on memory. Appl. Cogn. Psychol. 35, 1125-1132. doi: 10.1002/acp.3838

Riesthuis, P., Otgaar, H., Mangiulli, I., and de Tauzia, R. (2020). Adopting a fictitious autobiography: fabrication inflation or deflation? Memory 28, 741752. doi: 10.1080/09658211.2020.1771371
Romeo, T., Otgaar, H., Smeets, T., Landstrom, S., and Boerboom, D. (2018). The impact of lyingabout a traumatic virtual reality experience on memory. Mem. Cogn. 47, 485-495. doi: 10.3758/s13421-018-0885-6

Romeo, T., Otgaar, H., Smeets, T., Landström, S., and Jelicic, M. (2019). The memory-impairingeffects of simulated amnesia for a mock crime. Appl. Cogn. Psychol. 33, 983-990. doi: 10.1002/acp.3508

Rossi-Arnaud, C., Spataro, P., Bhatia, D., Doricchi, F., Mastroberardino, S., and Cestari, V. (2020). Long-lasting positive effects of collaborative remembering on false assents to misleading questions. Acta Psychol. 203:102986. doi: 10.1016/ j.actpsy.2019.102986

Small, H. (1973). Co-citation in the scientific literature: a new measure of the relationship between two documents. J. Assoc. Inf. Sci. Technol. 24, 265-269. doi: 10.1002/asi.4630240406

Sonkusare, S., Breakspear, M., and Guo, C. (2019). Naturalistic stimuli in neuroscience: critically acclaimed. Trends Cogn. Sci. 23, 699-714.

Su, H. N., and Lee, P. C. (2010). Mapping knowledge structure by keyword cooccurrence: a first look at journal papers in technology foresight. Scientometrics 85, 65-79. doi: 10.1007/s11192-010-0259-8

Sun, X., Punjabi, P. V., Greenberg, L. T., and Seamon, J. G. (2009). Does feigning amnesia impair subsequent recall? Mem. Cogn. 37, 81-89. doi: 10.3758/MC.37.1

Van Eck, N. J., and Waltman, L. (2014). "Visualizing bibliometric networks," in Measuring Scholarly Impact: Methods and Practice, eds Y. Ding, R. Rousseau, and D. Wolfram (Berlin: Springer), 285-320.

Van Eck, N. J., Waltman, L., Dekker, R., and van den Berg, J. (2010). A comparison of two techniques for bibliometric mapping: multidimensional scaling and VOS. J. Am. Soc. Inf. Sci. Tec. 61, 2405-2416. doi: 10.1002/asi.21421

Van Oorsouw, K., and Giesbrecht, T. (2008). Minimizing culpability increases commission errors in a mock crime paradigm. Legal Criminol. Psychol. 13, 335-344. doi: 10.1348/135532507X228539

Van Oorsouw, K., and Merckelbach, H. (2004). Feigning amnesia undermines memory for a mock crime. Appl. Cogn. Psychol. 18, 505-518. doi: 10.1002/acp.99

Van Oorsouw, K., and Merckelbach, H. (2006). Simulating amnesia and memories of a mock crime. Psychol. Crime Law 12, 261-271. doi: 10.1080/ 10683160500224477

Vieira, K. M., and Lane, S. M. (2013). How you lie affects what you remember. J. Appl. Res. Mem. Cogn. 2, 173-178. doi: 10.1016/j.jarmac.2013.05.005

Vo, T. V. A., Gunderson, C. A., and Ten Brinke, L. (2021). How deception and believability feedback affect recall. Memory 1-9. doi: 10.1080/09658211.2021. 1883064

Vrij, A. (2008). Detecting Lies and Deceit: Pitfalls and Opportunities. Chichester: Wiley.

Walczyk, J. J., Harris, L. L., Duck, T. K., and Mulay, D. (2014). A social-cognitive framework forunderstanding serious lies: activation-decision-constructionaction theory. New Ideas Psychol. 34, 22-36. doi: 10.1016/j.newideapsych.2014. 03.001

Zaragoza, M. S., Payment, K. E., Ackil, J. K., Drivdahl, S. B., and Beck, M. (2001). Interviewing witnesses: forced confabulation and confirmatory feedback increase false memories. Psychol. Sci. 12, 473-477. doi: 10.1111/14679280.00388

Zhong, B., Wu, H., Li, H., Sepasgozar, S., Luo, H., and He, L. (2009). A scientometric analysis and critical review of construction related ontology research. Autom. Constr. 101, 17-31. doi: 10.1016/j.autcon.2018.12.013

Conflict of Interest: The authors declare that the research was conducted in the absence of any commercial or financial relationships that could be construed as a potential conflict of interest.

Publisher's Note: All claims expressed in this article are solely those of the authors and do not necessarily represent those of their affiliated organizations, or those of the publisher, the editors and the reviewers. Any product that may be evaluated in this article, or claim that may be made by its manufacturer, is not guaranteed or endorsed by the publisher.

Copyright (C) 2022 Battista and Otgaar. This is an open-access article distributed under the terms of the Creative Commons Attribution License (CC BY). The use, distribution or reproduction in other forums is permitted, provided the original author(s) and the copyright owner(s) are credited and that the original publication in this journal is cited, in accordance with accepted academic practice. No use, distribution or reproduction is permitted which does not comply with these terms. 